\title{
Assessment \\ of \\ Plutonium Storage Safety Issues \\ at \\ Department of Energy \\ Facilities

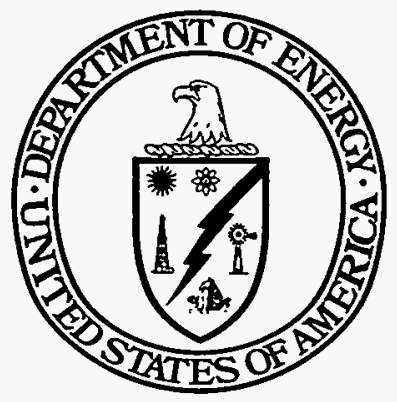 \\ January 1994
}

U.S. Department of Energy

Assistant Secretary for

Defense Programs

Washington, DG 20585 


\section{DISCLAIMER}

This report was prepared as an account of work sponsored by an agency of the United States Government. Neither the United States Government nor any agency thereof, nor any of their employees, makes any warranty, express or implied, or assumes any legal liability or responsibility for the accuracy, completeness, or usefulness of any information, apparatus, product, or process disclosed, or represents that its use would not infringe privately owned rights. Reference herein to any specific commercial product, process, or service by trade name, trademark, manufacturer, or otherwise does not necessarily constitute or imply its endorsement, recommendation, or favoring by the United States Government or any agency thereof. The views and opinions of authors expressed herein do not necessarily state or reflect those of the United States Government or any agency thereof. 


\section{DISCLAIMER}

Portions of this document may be illegible in electronic image products. Images are produced from the best available original document. 


\section{TABLE OF CONTENTS}

Summary

I. Introduction

II. Material Properties Relevant to Storage......................................... 3

II.A. Metal, Oxides, and Oxidation ............................................... 3

II.B. Reactions Involving Water .......................................... 5

II.C. Hydride ............................................................ 7

II.D. Plastics.and Other Organic Materials in Storage ................................ 7

II.E. Carbides and Nitride........................................................ 8

II.F. Pyrophoricity .......................................................... 8

II.G. Particle Size .......................................................... 10

III. Current Storage Practices..................................................... 12

III.A. Containers ............................................................. 12

III.B. Metal Storage............................................................... 12

III.C. Oxide Storage ..................................................... 15

III.D. Thermal Processing Practices at DOE Facilities.................................. 15

III.E. Storage Experience at Individual DOE Facilities ........................... 16

III.E.1. Rocky Flats Plant.................................................. 16

III.E.2. Los Alamos National Laboratory............................... 17

III.E.3. Hanford..................................................... 18

III.E.4. Savannah River Site................................................ 18

III.E.5. Argonne National Laboratory.................................... 19

III.F. Applicable DOE Orders. ............................................... 19

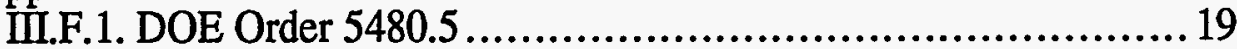

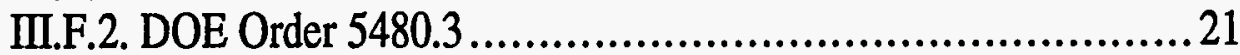

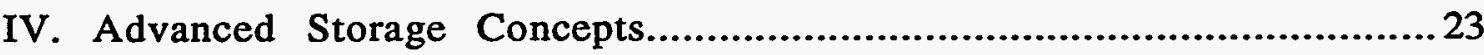

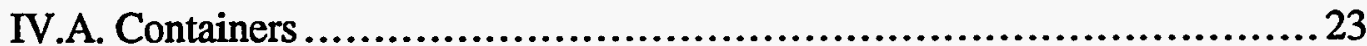

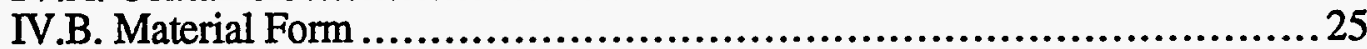

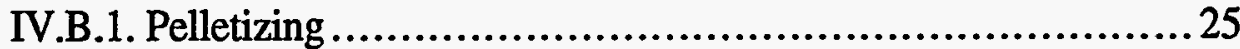

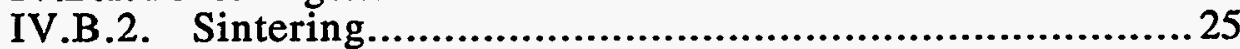

IV.B.3. Reduction of Oxide to Metal .............................26

IV.B.4. Alloying or Coating of Plutonium Metal to Reduce Corrosion. . 26

IV.C. Complex-21 Criteria..........................................................26

V. Hazard Analysis ............................................................... 30

V.A. Hazard Identification .................................................... 30

V.B. Fundamental Hazards Associated with Material Form .......................31

V.B.1. Chemical Reactivity .............................................. 31

V.B.2. Radiolytic Reactivity.................................................. 32

V.B.3. Helium Release.................................................... 34

V.B.4. Container Pressurization. .................................... 35

V.B.5. Airborne Release of Plutonium................................ 35 
V.B.6. Other Environmental, Safety, and Health Issues.................37

V.C. Material at Risk ........................................................ 38

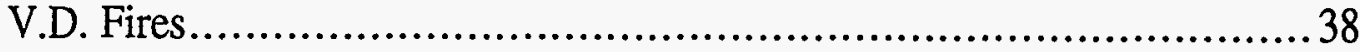

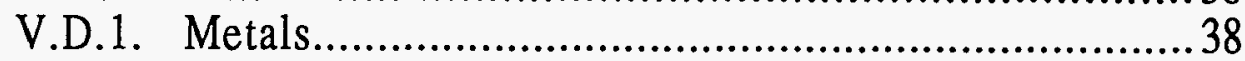

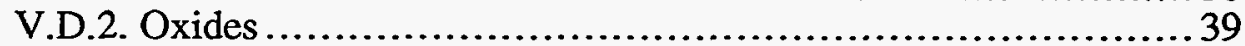

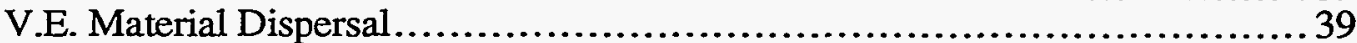

V.E.1. Material Dispersal in Fires..............................................39

V.E.2. Explosions and Pressurization.................................. 40

V.E.3. Spills................................................................ 40

V.E.4. Results.................................................. 41

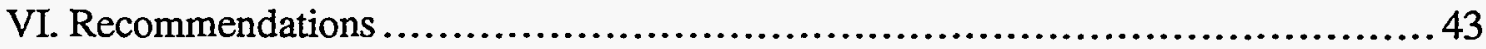

VII. Bibliography ................................................................. 46

Appendix A. Attendance List and Agenda for Plutonium Storage Workshop............. A1

Appendix B. Pelletizing of Plutonium Oxide.................................................. B1

Appendix C. Calculation of Worst-Case Pressure Rise for Stored Plutonium Oxide.... C1

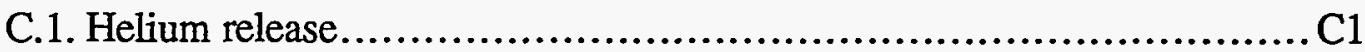

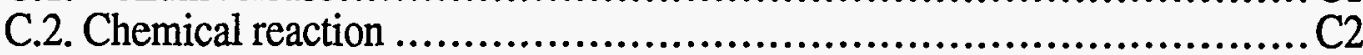

C.3. Radiolytic reaction ....................................................... 2

C.4. Thermal desorption ................................................... 3

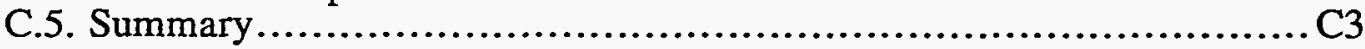

Appendix D. Summary of Calculations for Heat Generation, Temperature Rise, and Plutonium Dispersion. ........................................................... D1

D.1. Initial Calculational Assumptions ......................................... D1

D.1.a. Plutonium Properties ....................................... D1

D.1.b. Can Properties ........................................... 1

D.1.c. Bounding Corrosion Estimates for Rocky Flats Unalloyed Metal Storage ............................................................. D1

D.2. Temperature Rise Sample Calculation ....................................... D2

D.3. Conduction and Radiation Sample Calculations.......................... D3

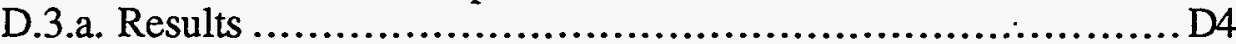

D.4. Mechanical Energy Equivalent in Pressurized Storage Containers........... D5 


\section{LIST OF FIGURES}

Page

Figure 1. Desorption of Water from $\mathrm{PuO}_{2}$ Surface Saturated at $27^{\circ} \mathrm{C}$............... 6

Figure 2. Plutonium Ignition Behavior ....................................... 10

Figure 3. Pu Metal Storage Container, Short Term Duration.......................24

Figure 4. Pu Metal Storage Container, Intermediate to Long Term Duration........24

Figure 5. Pu Oxide Storage Container, Stabilized, Unqualified Oxide, Short Term Duration ................................................... 24

Figure 6. Pu Oxide Storage Container, Qualified Oxide, Short, Intermediate and Long Term Duration .24

\section{LIST OF TABLES}

Table 1. Plutonium storage practices at DP sites............................... 13

Table 2. $\quad A_{1}$ and $A_{2}$ values for radionuclides ............................... 22

Table 3. Definition of mass limits for material at risk ............................ 38

Table 4. Material at risk as a result of certain accident scenarios..................42 


\section{Summary}

The Department of Energy (DOE) mission for utilization and storage of nuclear materials has recently changed as a result of the end of the "Cold War" era. Past and current plutonium storage practices largely reflect a temporary, in-process, or in-use storage condition which must now be changed to accommodate longer-term storage. This report summarizes information concerning current plutonium metal and oxide storage practices which was presented at the Office of Defense programs (DP) workshop in Albuquerque, New Mexico on May 26-27, 1993 and contained in responses to questions by DP-62 from the field organizations.

The scope of the presentations and discussions was limited to packaging and interim storage of weapons-grade, fuel-grade, and power-grade plutonium. Consideration was given to current and potential interim storage criteria as they would evolve into longer term storage in Complex 21 facilities. Existing storage and handling requirements for plutonium metal and oxide are currently covered in DOE Orders 5480.3 and 5480.5 as well as orders covering criticality limits, safeguards and security, and transportation. Storage of residues, waste, or pyrophoric plutonium materials are not included. The principal difference between interim and long-term storage is the need for transfer of plutonium from a contaminated glove box environment into an improved, hermetically sealed storage container without the inclusion of plastic or other organic materials. The improved container can then be safely stored within structures and vaults meeting Safeguards criteria.

Material requirements were developed for interim storage of both plutonium metal and oxide. These are:

- Metal must be of a size configuration that makes it non-pyrophoric;

- No plastic or organic materials shall be in direct contact with stored plutonium;

- Thermally stabilize oxide at $1000^{\circ} \mathrm{C}$ with subsequent cooling and packaging in a dry atmosphere.

Additional requirements for packaging and storage are:

- Move toward containers which are hermetically sealed and away from containers using organic materials for seals;

- Coordinate plutonium inventories and inspections so as to minimize radiation exposure.

A new interim guidance for the safe storage of plutonium metal and oxide has evolved from the assessments developed within this report. 


\section{Introduction}

On April 30, 1993, EG\&G Rocky Flats, Inc., the management and operating contractor at the Rocky Flats Plant, notified the Department of Energy (DOE) that the company had failed to inspect stored metallic plutonium in accordance with schedules established in internal plant safety procedures. Concerns focused on plutonium metal and its corrosion products since they are considered to be pyrophoric and because they might spontaneously ignite in air under certain conditions. As a result, it has been common practice to periodically inspect stored material for signs of corrosion. If remediation was deemed necessary, corrosion products were removed and thermally stabilized by oxidation at high temperature and the metal was repackaged. To remedy the immediate situation, EG\&G Rocky Flats was asked to develop a plan and detailed procedures for necessary inspections, cleaning and repackaging.

In order to determine whether similar problems exist at other DOE facilities, the Office of Defense Programs (DP) requested all Operations Offices to provide information on practices at other DP plutonium storage sites and organized a workshop on storage issues. The workshop was held in Albuquerque, New Mexico, on May 26 and 27, 1993.

The objectives of the workshop were to:

1) Identify plutonium (metal and oxide) storage issues at Department of Energy (DOE) sites;

2) Evaluate whether there are any immediate safety concerns for site workers and the public;

3) Initiate development of DOE-wide criteria for interim, safe storage of plutonium metal and oxides, including requirements for surveillance, good practices, etc.; and

4) Discuss the relationships between the requirements for current, near-term, and long-term storage.

The processing and storage of plutonium residues, ${ }^{238} \mathrm{Pu}$, and $\mathrm{Pu}$-bearing liquids were excluded from the scope of the workshop and are not considered in this report.

The agenda for the workshop (Appendix A) was developed by an ad hoc steering group of DOE Headquarters personnel and contractors with recognized expertise in plutonium handling and storage. All DOE sites were represented at the workshop as well as non-DP sites at which significant quantities of plutonium are stored. Participants in the workshop, including designated presenters, are also listed in Appendix A. The program was coordinated with representatives from Operations Offices and Headquarters Program Offices. It included a review of the technical basis for plutonium storage practices, descriptions of current and planned near-term storage practices at each facility, and a presentation of advanced concepts for long-term storage being developed as part of the weapons complex reconfiguration (i.e., Complex-21) effort. Based on the presentations and subsequent discussions, a general consensus was achieved on the hazards associated with the storage of plutonium metal and oxide, and on recommendations to DOE for enhancing the safety of the Department's storage practices.

The scope of this report is limited to an analysis of storage practices for extracted plutonium metal and oxide. Materials having distributions of plutonium isotopes in the weapons-grade range are considered; those rich in ${ }^{238} \mathrm{Pu}$ are excluded. Storage of plutonium in aqueous solution, plutonium in pits, plutonium in residues (less than 50 mass \% Pu), and metallic turnings and particles with specific surface areas greater than $1 \mathrm{~cm}^{2} / \mathrm{g}$ is not included. This report examines issues pertinent to establishing standards for short-term (up to 10 years) and long-term (up to 100 years) storage. The ultimate disposition of plutonium is not addressed. 
Information presented at the workshop along with that obtained from written responses to requests from DP is the basis for this analysis. Properties relevant to safe storage of metal and oxide are discussed in Section II. Current storage practices at DOE facilities are reviewed in Section III. Advanced storage concepts and a brief hazard analysis that attempts to bound the risks from the current storage practices are described in Sections IV and V, respectively. Section VI includes recommendations for improving storage practices. Section VII contains a bibliography for further, suggested reading. References cited within the text are found at the bottom of the relevant pages.

The following authors contributed to this report:

Lisa K. Chan, Department of Energy, Office of Defense Programs

Dae Y. Chung, Department of Energy, Office of Defense Programs

Donald T. Chung, SCIENTECH, Inc.

Raymond Cooperstein, Department of Energy, Office of Defense Programs

Rowland E. Felt, Westinghouse Idaho Nuclear Company

John M. Haschke, Los Alamos National Laboratory

Joseph C. Martz, Los Alamos National Laboratory

David Michlewicz, Department of Energy, Office of Defense Programs

Jofu Mishima, Science Applications International Corporation

Thomas O'Connor, Department of Energy, Office of Environment, Safety, and Health

David M. Pinkston, Science Applications International Corporation

Michael F. Stevens, Los Alamos National Laboratory

Alan K. Williams, Science Applications International Corporation 


\title{
II. Material Properties Relevant to Storage
}

\author{
II.A. Metal, Oxides, and Oxidation
}

The chemistry of plutonium is unique, but certain aspects closely parallel those of other actinide elements. Large pieces of plutonium metal react slowly with the oxygen in air at room temperature to form plutonium oxides. The rate of oxidation is dependent on a number of factors. These include: 1) temperature, 2) surface area of the reacting metal, 3) oxygen concentration, 4) concentration of moisture and other vapors in the air, 5) the type and extent of alloying, and 6) presence of a protective oxide layer on the metal surface. ${ }^{1}$ The rate of oxidation increases with increases in the first four factors and decreases with the last. 2,3 Alloying can either increase or decrease the oxidation rate, depending on the alloying metal. The oxide formed on the surface of gallium-containing alloys is very adherent and retards further oxidation. ${ }^{4}$ Of all these factors, moisture has a large effect on the oxidation rate and is especially significant in evaluating conditions for storing plutonium metal and oxide.

Several plutonium oxides can be formed from oxidation of metal or decomposition of plutonium compounds. Oxide phases corresponding to sesquioxide $\left(\mathrm{Pu}_{2} \mathrm{O}_{3}\right)$ and dioxide $\left(\mathrm{PuO}_{2}\right)$ compositions have been identified and are well characterized. 5,6 Oxides with stoichiometric compositions between the sesquioxide and dioxide form under certain conditions. The phase previously identified as plutonium monoxide $(\mathrm{PuO})$ is actually an oxide carbide $\left(\mathrm{PuO}_{0.6} \mathrm{C}_{0.4}\right){ }^{7}$ $\mathrm{Pu}_{2} \mathrm{O}_{3}$ is pyrophoric in air ${ }^{8}$ and rapidly forms dioxide while releasing $54 \mathrm{kcal}$ of heat $/ \mathrm{mol}$ of $\mathrm{PuO}_{2} \cdot{ }^{9}$ The dioxide is inert in air, but reportedly reacts slowly with water vapor at elevated

1C.A. Colmenares, Prog. Solid State Chem. 9 (1984) 257.

2J.L. Stakebake and L.M. Steward, J. Electrochem. Soc., 119 (1972) 730.

3K. Terada, R.L. Meisel, and M.R. Dringman, J. Nucl. Mater., 30 (1969) 340.

${ }^{4}$ J.L. Stakebake and L.A. Lewis, "High Temperature Oxidation of Plutonium-1 wt\% Gallium in 94.5\% Nitrogen/5.5\% Oxygen Atmospheres," Rockwell International Aerospace Operations Report, Rocky Flats Plant, CO, RFP-3933 (November 1986).

5L.R. Morss, "Thermodynamic Properties" in The Chemistry of the Actinide Elements 2nd Edition, vol. 2, eds. J.J. Katz, G.T. Seaborg, and L.R. Morss (Chapman \& Hall, New York, 1986) chapter 17.

6J.M. Haschke, "Hydrolysis of Plutonium: Plutonium-Oxygen Phase Diagram" in Transuranium Elements a Half Century, eds. L.R. Morss and J. Fuger (American Chemical Society, Washington, D.C., 1992) chapter 40.

7D.T. Larson and John M. Haschke, Inorg. Chem. 20 (1981) 1945.

8J.M. Cleveland, "Compounds of Plutonium" in Plutonium Handbook a Guide to the Technology, Vol I and II, ed. O.J. Wick (American Nuclear Society, La Grange Park, IL, 1980) Chapter 12.

9L.R. Morss, "Thermodynamic Properties" in The Chemistry of the Actinide Elements 2nd Edition, vol. 2, eds. J.J. Katz, G.T. Seaborg, and L.R. Morss (Chapman \& Hall, New York, 1986) chapter 17. 
temperatures to form a higher oxide $\left(\mathrm{PuO}_{2.2}\right)$ plus hydrogen. ${ }^{10}$ Substoichiometric oxides or "suboxides" with compositions near dioxide (e. g., $\mathrm{PuO}_{1.98}$ ) oxidize slowly to $\mathrm{PuO}_{2}$. The heat liberated from the oxidation of $\mathrm{PuO}_{1.98}$ is only $4.54 \mathrm{kcal} / \mathrm{mol}$ compared to $252.8 \mathrm{kcal} / \mathrm{mol}$ for the oxidation of $\mathrm{Pu}$ metal to $\mathrm{PuO}_{2}$.

The formation of oxide from metal is accompanied by a large volume expansion (at least $40 \%$ ) which may bulge or breach the primary container. Case studies show that mechanical wedging resulting from this expansion can even breach a second metal container, resulting in localized contamination release and possible exposure of vault personnel. ${ }^{11}$ Oxidation of the metal and rupture of the container by mechanical wedging are prevented if the storage container is hermetically sealed.

Properties of the dioxide may vary with the method of preparation. The particle size distribution and specific surface area of process oxide prepared by pyrolysis or calcination of a precipitate such as the oxalate, nitrate or peroxide may differ substantially from those of dioxide obtained by oxidation of the metal. ${ }^{12}$ Whereas high temperature $\left(>500^{\circ} \mathrm{C}\right)$ oxidation of metal yields an oxide with a relatively low specific surface area $\left(<0.1 \mathrm{~m}^{2} / \mathrm{g}\right)$, the product obtained by pyrolysis of oxalate has a high specific area $\left(10-50 \mathrm{~m}^{2} / \mathrm{g}\right)$ that varies with calcination temperature. The specific areas of oxides formed by oxidation of metal in air at room temperature are typically in the 10$20 \mathrm{~m}^{2} / \mathrm{g}$ range. ${ }^{13}$ The purity of process oxides may also vary with the conditions of calcination due to differences in the amount of anion residues remaining in the product after calcination.

Although chemical corrosion is not a concern with $\mathrm{PuO}_{2}$, reactions involving "oxides" are known. In addition to the pyrophoric $\mathrm{Pu}_{2} \mathrm{O}_{3}$, oxides generated by the corrosion of metal in oxygendeficient atmospheres containing hydrogen may contain metal fines and small amounts of hydride. Experience indicates these products oxidize in a relatively rapid, but safe manner. However, this general rule should not be considered applicable if the oxide contains large amounts of potentially reactive impurities such as hydride. Reactive impurities can pose a fire hazard by acting as an initiation source for combustible materials. The risk of a large fire is virtually eliminated if the amount of combustible material in the storage environment is limited.

The dioxide has an active surface that strongly adsorbs atmospheric molecular species and the material is highly reactive from a radiolytic perspective. Together, the absorption behavior and high specific surface areas of process oxides can result in adsorption of large amounts of water, carbon dioxide, organic molecules, etc. from the process environment. Radiolytic decomposition of adsorbed species by alpha particles from radioactive decay of plutonium generates gases (e. g., $\mathrm{H}_{2}, \mathrm{CO}$ and $\mathrm{O}_{2}$ ) that are not strongly adsorbed by the oxide. The resulting pressurization of a sealed container can lead to bulging or rupture. Since adsorbed species are removed by heating

10J. L. Stakebake, D.T. Larson, and J.M. Haschke, J. Alloys Comp., in publication; also available as Los Alamos Report LA-UR-93-0040 (1993).

11J.M. Haschke and J.C. Martz, "Metal-Oxide Chemistry and Storage," presentation to the DOE workshop on plutonium storage, Los Alamos Report LA-CP-93-159, Albuquerque, NM (May 26, 1993).

12J.D. Moseley and R.O. Wing, "Properties of Plutonium Dioxide," Dow Chemical Company Report, Golden, CO, RFP-503 (August 1965).

13J.L. Stakebake and M.R. Dringman, J. Nucl. Mat. 23 (1967) 349. 
oxide to an elevated temperature in air, thermal processing may be used to remove adsorbates from the oxide prior to storage. Care must be taken to prevent re-exposure of processed material to moisture and other contaminants before packaging. Thermal desorption of gases due to internal or external heating of a sealed storage container can also generate high pressures.

Alpha decay of plutonium provides another potential source for pressurizing sealed containers. Decay of ${ }^{239} \mathrm{Pu}$ produces helium at a rate of $1.19 \times 10^{-4} \mathrm{~mol} \mathrm{He} / \mathrm{kg} \mathrm{Pu} \cdot \mathrm{yr}$. $\left(1.05 \times 10^{-4} \mathrm{~mol}\right.$ $\mathrm{He} / \mathrm{kg} \mathrm{PuO}_{2} \cdot \mathrm{yr}$.). Whereas the helium produced in oxide diffuses out of the solid particles, ${ }^{14}$ helium generated in bulk metal is retained and accumulates as small bubbles along grain boundaries. ${ }^{15}$ The contribution of helium to pressurization of an oxide storage container is negligible for near-term storage, but must be considered if the storage period is extended. 16

\section{II.B. Reactions Involving Water}

Water vapor accelerates the oxidation of plutonium by oxygen and reacts directly with the metal. ${ }^{17}$ The process by which water enhances the rate remains open to debate, but it is generally believed that the process involves formation of plutonium hydride. The net result is that the oxidation rate is about ten times higher in humid air than in dry air at room temperature. For this reason, plutonium metal has routinely been handled in a very dry atmosphere such as one with a $-40^{\circ} \mathrm{C}$ dew point. Nitrogen or argon can be effective in reducing oxidation of plutonium in glove boxes and enclosures if water vapor can also be excludes. Rapid oxidation does not occur if oxygen is present at a level of $5 \%$ in nitrogen or argon. ${ }^{18}$ However, if $1.3 \%$ moisture (50\% relative humidity) accompanies the oxygen, then rapid metal oxidation can be anticipated. Water is not used in glove box enclosures containing plutonium metal, the principal source of both oxygen and water is diffusion through enclosure gloves and plastic bag-out ports.

Plutonium dioxide is hygroscopic and a high surface area material which can adsorb up to $8 \%$ of its weight as water on the surface. The quantity adsorbed is a direct function of the surface area of the oxide. As shown by data in Figure 1, absorbed moisture can be removed by heating the oxide. Approximately $2 / 3$ of the moisture is only physically absorbed and can be removed by minimal heating at $50-100^{\circ} \mathrm{C}$. Temperatures up to $1000^{\circ} \mathrm{C}$ are necessary to remove the remaining chemisorbed water.

The principal hazard associated with adsorbed water is pressurization of a sealed oxide container through any of several separate processes including thermal desorption of water, radiolysis to form oxygen and hydrogen, or direct reaction with the oxide to form a higher oxide and hydrogen

14B.A. Mueller, D.D. Rohr, and R.N.R. Mulford, "Helium Release and Microstructural Changes in ${ }^{238} \mathrm{PuO}_{2}$," Los Alamos Report LA-5524, April 1974.

15M.F. Stevens, T.G. Zocco, and J.H. Steele, "Bubble-Void Formation in Delta Phase Plutonium (U)," Los Alamos Report MST-5-88-9, August 25, 1988 (Secret/RD).

16J.C. Martz, "Analysis of Plutonium Storage Pressure Rise," US DOE Report, Los Alamos, NM, NMT-5:92-328 (July 1992).

17J.L. Stakebake, "Characterization of the Plutonium-Water Reaction: Reaction Kinetics Between 200 and $350^{\circ} \mathrm{C}$," in Transuranium Elements: A Half Century, L.R. Moss and J. Fuger eds., American Nuclear Society, Washington D.C. (1992), chapter 27.

18J.L. Stakebake and L.A. Lewis, "High Temperature Oxidation of Plutonium-1 wt\% Gallium in 94.5\% Nitrogen/5.5\% Oxygen Atmospheres," Rockwell International Aerospace Operations Report, Rocky Flats Plant, CO, RFP-3933 (November 1986). 
gas. Storage requirements for oxide have generally required a prior calcination temperature of 650 $700^{\circ} \mathrm{C}$ to minimize container pressurization. Data for oxide with a specific surface area of $17 \mathrm{~m}^{2} / \mathrm{g}$ (cf. Figure 1) show that this treatment leaves about $2 \mathrm{mg}$ of water per gram $\mathrm{PuO}_{2}$. For a typical storage configuration ( $3 \mathrm{~kg}$ of oxide with 2 liters free volume) the pressure could ultimately exceed 60 psig after calcination at $650-700^{\circ} \mathrm{C}$. If the stored oxide has a surface area of $50 \mathrm{~m}^{2} / \mathrm{g}$, the pressure could reach 180 psig.

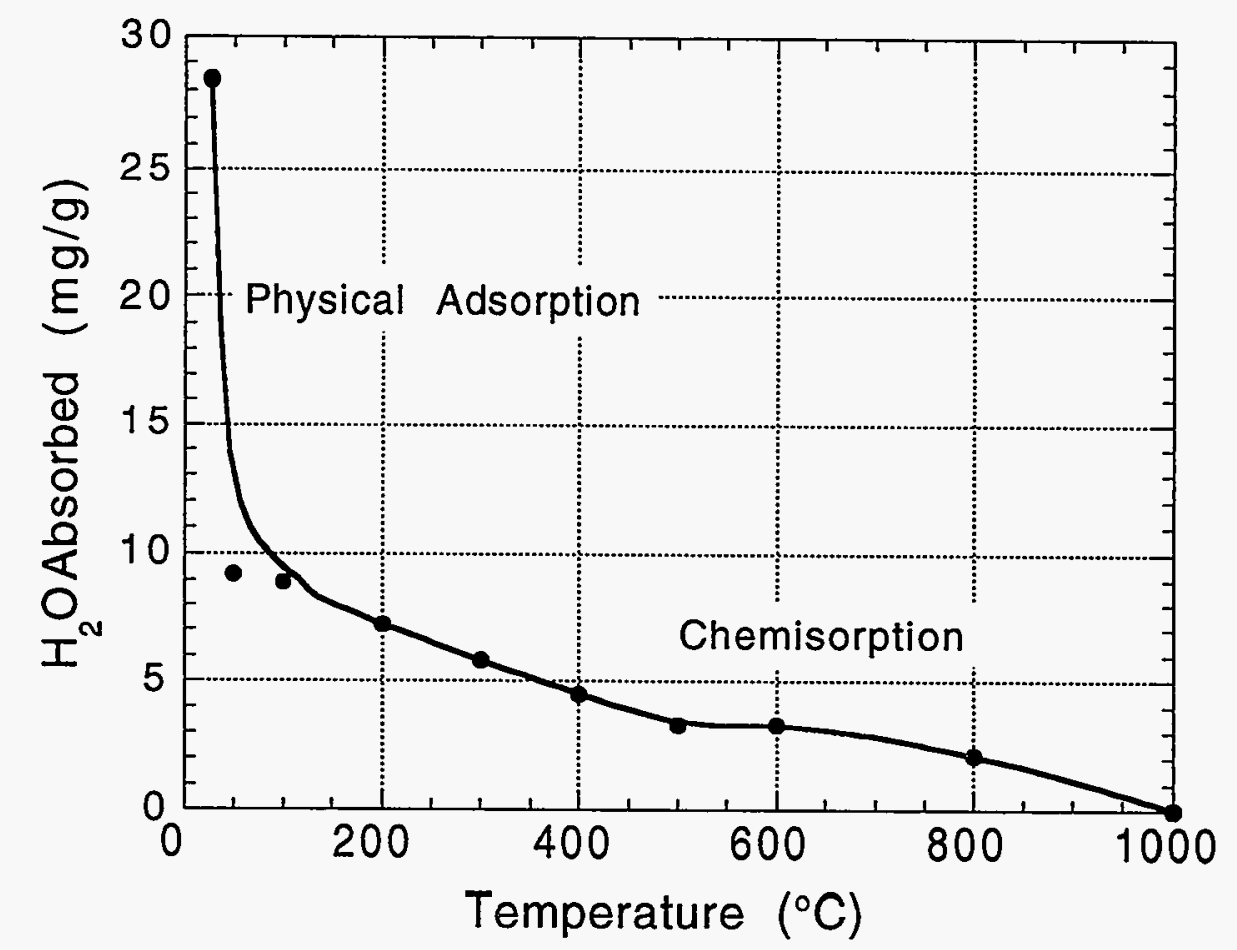

Figure 1. The temperature dependence of water desorption from plutonium dioxide in vacuum. Data are from a sequence of isothermal measurements with a $\mathrm{PuO}_{2}$ sample having a specific surface area of $17 \mathrm{~m}^{2} / \mathrm{g} .19$

Pressurization of oxide containers might be prevented by use of sealed containers fitted with durable, high-efficiency metal filters. Although radiolytic gases can escape without release of plutonium-containing particles, air (possibly moist) is able to enter the container. Radiolysis of nitrogen/oxygen mixtures forms large amounts of $\mathrm{N}_{2} \mathrm{O}, \mathrm{NO}_{2}$, and $\mathrm{N}_{2} \mathrm{O}_{4}{ }^{20}$ When water is present, nitrogen oxides form a highly-corrosive (e.g. $\mathrm{HNO}_{3}$ ) environment. ${ }^{21}$ However, a serious concern exists regarding the "masking" of filter media. Sintered metal and fibrous filters can have the pores masked if the surface is covered by a fine powder such as might occur if the container is overturned. Once masked, the filter would only be a structurally weak portion of the container while not allowing the passage of pressurized gases.

19J.L. Stakebake and L.M. Steward, J. Colloid Interface Sci. 42 (1973) 581.

20J.L. Stakebake, R.W. Losier, and C.A. Chambers, Appl. Spectrosc. 25 (1971) 70.

21P.G. Stecher, M.J. Finkel, and O.H. Siegmund, The Merck Index, Seveth Edition, Merck and Co., Inc., Rahway, NJ (1960). 


\section{II.C. Hydride}

Plutonium hydride $\left(\mathrm{PuH}_{\mathrm{x}}, 2<\mathrm{x}<3\right)$ forms during corrosion of plutonium metal by hydrogen from water, organic materials and other sources. ${ }^{22,23}$ The quantity of hydride produced depends on the rate of hydrogen formation and on the magnitude of the hydrogen-containing source. The presence of oxygen or moisture with the hydrogen results in an oxide+hydride mixture. The reactivity of plutonium hydride in air depends on factors such as particle size, presence/absence of protective oxide layer, and hydrogen:plutonium ratio, $\mathrm{x}$. Finely divided hydride is pyrophoric in air at room temperature. Thus, the only safe practice is to handle and store hydride in a dry, oxygen-free atmosphere free of unnecessary combustibles.

Hydride is rapidly oxidized by dry air at room temperature to produce $\mathrm{PuO}_{2}$ and $\mathrm{H}_{2}$ and reacts with nitrogen at $250^{\circ} \mathrm{C}$ to form plutonium nitride $(\mathrm{PuN})$. Reaction of $\mathrm{PuH}_{2}$ with $\mathrm{O}_{2}$ releases $213.5 \mathrm{kcal} / \mathrm{mol}$.

\section{II.D. Plastics and Other Organic Materials in Storage}

Contamination-free exterior surfaces have typically been required for containers used in shipment and vault storage of plutonium. This has usually been accomplished by a "bag-out" operation in which a sealed plastic bag is used to contain plutonium contamination. Plutonium metal buttons were bagged out and sealed in food-pack cans for storage. If the button was not placed in a metal can before bag out, it remained in direct contact with the plastic inside the sealed container. The temperature of the stored metal is generally slightly elevated due to the heat from radioactive decay.

Polyethylene and polyvinyl chloride (PVC) are used as bagging materials and both deteriorate under heat and radiation and generate undesirable gaseous products. ${ }^{24}$ Experiments show that low-density polyethylene can be used to temperatures as high as $300^{\circ} \mathrm{C}$ without excessive degradation to form hydrogen. The maximum service temperature for PVC is approximately $85^{\circ} \mathrm{C}$. In addition to $\mathrm{H}_{2}$, thermal degradation of this plastic produces gaseous $\mathrm{HCl}$ that corrosively reacts with other materials to form hydrogen. Polyethylene is the preferred bagging material, but is more difficult to heat-seal. Radiolysis of the two plastics yields large amounts of the same gaseous products as pyrolysis. The radiolysis rate is a function of the surface area of plastic in intimate contact with plutonium-containing material. ${ }^{25}$ Due to the limited escape depth of alpha particles from dense materials, a film of contamination or fine oxide particles deposited on

22J.M. Haschke, "Actinide Hydrides," in Topics in f-Element Chemistry: Synthesis of Lanthanide and Actinide Compounds Volume II, Chapter 1, G. Meyer and L.R. Morss eds., Kluwer Academic Publishers, Dordrecht, Netherlands (1991).

23J.M. Haschke and T.H. Allen, "Hydrogen Corrosion of Plutonium in Nuclear Weapons (U)," Defense Research Review (U), 4 (1992) (S/RD).

${ }^{24}$ A.R. Kazanjian, P.M. Arnold, W.C. Simmons, and E.L. D'Amico, "Gas Generation Results and Venting Study for Transuranic Waste Drums," Rocky Flats Report RFP-3739, September 23, 1985.

${ }^{25}$ G. Friedlander, J.W. Kennedy, and J.M. Miller, Nuclear Radiochemistry, 2nd ed., John Wiley and Sons, Inc., New York (1966). 
the plastic is comparable to a massive piece of metal in promoting radiolytic degradation. If the plastic is outside of a sealed can containing the metal button, degradation of the plastic is reduced because the only source of plutonium-containing particles is contamination on the exterior of the can.

Reaction of plutonium with hydrogen is the principal corrosion concern for metal that is not isolated from the gases formed by degradation of plastics. ${ }^{26}$ At room temperature, the reaction of metal with $\mathrm{H}_{2}$ is $10^{6}$ times more rapid than the reaction with $\mathrm{O}_{2 .}{ }^{27}$ Any oxygen initially present in the sealed storage container reacts with hydride or metal to generate an oxygen-free atmosphere. In the absence of oxygen all $\mathrm{PuO}_{2}$ remaining on the surfaces of hydride and metal is slowly reduced to pyrophoric $\mathrm{Pu}_{2} \mathrm{O}_{3} .28$ These reactions prevent pressurization of the container and the mixture of metal, hydride and oxide is stable as long as the container is sealed. Once the storage container is opened, airborne hydride and sesquioxide will ignite and burn with formation of sparks. Special precautions are necessary when handling such containers to avoid sparks that spread contamination and might ignite combustible materials.

Plutonium oxide is never "bagged-out" in direct contact with plastic. Cans containing oxide are either sealed by mechanically crimping or by taping on a slip-lid. When the can is "bagged-out" only the inner surface of the plastic bag and outer surface of the can are contaminated. Radiolytic degradation of the bag over time ultimately results in failure of the plastic as a containment barrier. Use of a second sealed can over the plastic bag prevents the release of contamination, but this outer can may pressurize as radiolytic gases are formed.

\section{II.E. Carbides and Nitride}

Plutonium carbides, oxycarbides and nitride are reactive and potentially pyrophoric materials that could pose handling problems if exposed to air or oxygen-containing atmospheres.29 These compounds react readily with moisture to form gaseous products such as methane, acetylene and ammonia. Since plutonium compounds of this type have been prepared at several sites and may have been "temporarily" stored under special conditions (hermetically sealed and handled under an inert atmosphere) without first oxidizing them, caution should be exercised in opening cans that might contain such materials.

\section{II.F. Pyrophoricity}

Many elements exist in nature as oxides since the metallic form is chemically reactive in air. Their behavior is described as pyrophoric only if the oxide forms at a rapid, sustained rate at ambient temperature. The alkaline metals such as sodium, potassium and lithium react violently with moist air, forming hydrogen which ignites and burns. Like alkaline earth metals such as magnesium and beryllium, the actinide elements such as thorium, uranium and plutonium will sustain combustion and burn after ignition at elevated temperatures.

${ }^{26}$ H.H. Van Tuyl, "Packaging of Plutonium for Storage or Shipment," Internal Report, Pacific Northwest Laboratory, Richland, WA (March 1981).

27J.M. Haschke and J.C. Martz, "Interim Storage of Excess Plutonium: An Assessment of Options (U)," US DOE Report, Los Alamos, NM, LA-12624-MS (July 1993) (S/RD).

28D.T. Larson and John M. Haschke, Inorg. Chem. 20 (1981) 1945.

29J.M. Cleveland, The Chemistry of Plutonium, American Nuclear Society, La Grange Park, IL (1979). 
When heated to its ignition temperature, plutonium reacts at an accelerated oxidation rate which sustains continued oxidation. ${ }^{30}$ Burning metal liberates $1.0 \mathrm{kcal}$ of heat per gram of plutonium. The burning temperature depends on the rate of heat dissipation to the surroundings and the rate of heat generation, which is dependent on the surface area of oxidizing metal. Temperatures of plutonium fires usually exceed the melting temperature of plutonium metal $\left(640^{\circ} \mathrm{C}\right)$ which causes the material to consolidate into a molten configuration. As such, finely divided metal, turnings, and casting skulls tend to ignite readily and achieve a high initial temperature which lasts until melting occurs and the surface area is reduced.

The oxide layer that forms during burning attenuates diffusion of air to the oxide-metal interface and limits the oxidation rate of plutonium. The burning process is similar to that of a charcoal briquette. The oxidation rate of $\mathrm{Pu}$ in air at temperatures above $500^{\circ} \mathrm{C}$ is constant with a value of $0.2 \mathrm{~g} \mathrm{PuO}_{2} / \mathrm{cm}^{2}$ min. ${ }^{31}$ Since a $2 \mathrm{~kg}$ plutonium button has an initial surface area on the order of $100 \mathrm{~cm}^{2}$, a period of $2-4$ hours is required for complete oxidation. Thus, the heat of combustion is dissipated over a relatively long period of time.

The ignition temperature of plutonium metal depends on the factors which increase the oxidation rate. As shown by Figure 2, finely divided plutonium metal, such as metal powder or fine machine turnings, ignites near $150^{\circ} \mathrm{C}$. This temperature is easily reached if a coexisting pyrophoric material such as hydride or sesquioxide spontaneously ignites at room temperature. Bulk or massive plutonium metal characterized as having a specific surface area less than $1 \mathrm{~cm}^{2} / \mathrm{g}$ requires temperatures in excess of $400^{\circ} \mathrm{C}$ to ignite. Based on Figure 2, Rocky Flats has defined pyrophoric plutonium metal to be "that metal which will ignite spontaneously in air at a temperature of $150^{\circ} \mathrm{C}\left(302^{\circ} \mathrm{F}\right)$ or below in the absence of external heat, shock, or friction." Many plutonium fires have occurred because samples containing finely divided metal have spontaneously ignited. Fires have not occurred with clean metal existing in large pieces that have the higher ignition temperature. Thus, massive plutonium is not considered pyrophoric or capable of self ignition. An investigation of two instances in which kilogram-sized plutonium pieces were observed to "spontaneously ignite" in air at room temperature shows that they had been exposed to unlimited sources of hydrogen for extended periods and that the samples were thermally insulated when ignition occurred. The amount of hydride present on these massive pieces apparently generated heat sufficient to raise the bulk temperature to the point of self ignition. These observations emphasize the need for well-characterized materials.

Pyrophoric materials have caused numerous incidents in which plutonium chips, lathe turnings and casting crucible skulls have ignited and burned. ${ }^{32,33,34}$ These ignition sources have resulted in several significant fires at plutonium metal processing facilities. Incidents involving spontaneous

${ }^{30}$ E.J. Chatfield, J. Nucl. Mater., 32 (1969) 218.

31J.M. Haschke, "Evaluation of Source-Term Data for Plutonium Aerosolization," US DOE Report, Los Alamos, NM, LA-12315-MS (July 1992).

32J.G. Schnizlein and D.F. Fischer, J. Electrochem. Soc., 115 (1968) 462.

${ }^{33}$ S.H. Pitts, Jr., Nuclear Safety, 9 (1968) 112.

${ }^{34}$ R.E. Felt, "Burning and Extinguishing Characteristics of Plutonium Metal Fires," Isochem Inc. Report, Richland, WA, ISO-756 (1967). 
plutonium initiation can be explained by the current understanding of the ignition and burning characteristics of plutonium metal. ${ }^{35}$

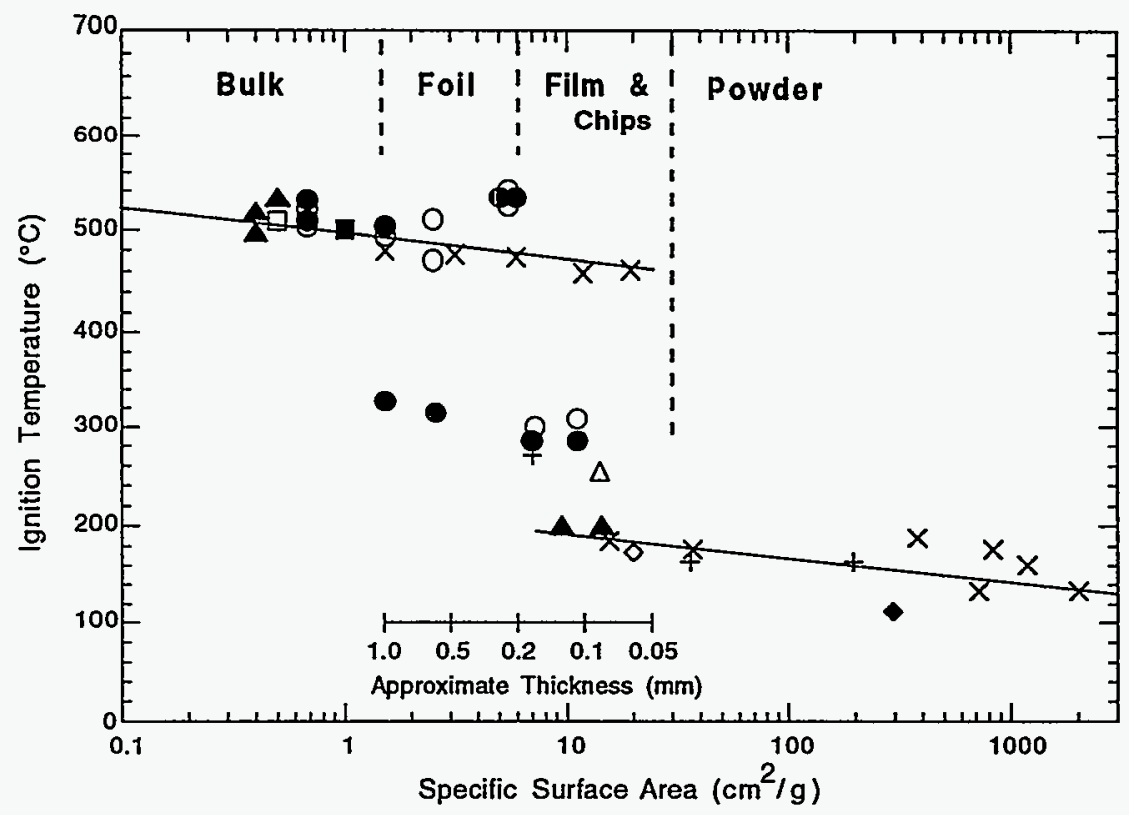

Figure 2. Measured ignition temperatures of plutonium as a function of specific surface area and metal dimension. ${ }^{36}$

\section{II.G. Particle Size}

The physical size of plutonium-containing particles in storage affects two unrelated phenomena. The first is the ability to absorb moisture and the second is the ability to disperse as a source term in accident conditions. 37 As with absorption, dispersibility increases with decreasing particle size. Massive $\mathrm{Pu}$ is not a dispersible form of plutonium; only after reaction to produce oxide particles does the material become potentially dispersible. As discussed in Section II.F, several hours are required to convert a typical $2 \mathrm{~kg}$ Pu button to oxide at the maximum oxidation rate in air with a concurrent volumetric expansion of product. Process oxide inherently exists in a potentially dispersible form.

The particle size distribution of an oxide is strongly dependent on the method of preparation. ${ }^{38}$ Oxide particles formed by calcination of oxalate, nitrate or peroxide and those obtained by slow

35J.C. Martz, J.M. Haschke, and J.L. Stakebake, "A Mechanism for Plutonium Pyrophoricity," manuscript submitted to J. Nucl. Mat., LA-UR-93-2655 (1993).

36J.L. Stakebake, "Plutonium Pyrophoricity," EG\&G Rocky Flats Division Report, Golden, CO, RFP-4517 (June 1992).

37J.M. Haschke, "Evaluation of Source-Term Data for Plutonium Aerosolization," US DOE Report, Los Alamos, NM, LA-12315-MS (July 1992).

38J.D. Moseley and R.O. Wing, "Properties of Plutonium Dioxide," Dow Chemical Company Report, Golden, CO, RFP-503 (August 1965). 
oxidation of metal by air at room temperature are totally within the dispersible range $(<10 \mu \mathrm{m}$ geometric dimension). Less than 0.1 mass $\%$ of the oxide produced by oxidation of the metal in air at temperatures above $500^{\circ} \mathrm{C}$ is in the dispersible range. ${ }^{37}$ These data imply that the dispersal risk of process oxide is approximately a thousand-fold greater than for metal in an equivalent scenario.

Heating plutonium oxide at high temperatures increases the particle size of the powder. Particle size data for preparation of oxide from oxalate show a progressive shift in the size distribution with calcination temperature. ${ }^{39}$ The percentages of particles with dimensions in excess of $5 \mu \mathrm{m}$ are 40 , 60 and $75 \%$ for calcination temperatures of 650,700 and $1000^{\circ} \mathrm{C}$, respectively. The difference for the respirable size range $(<3 \mu \mathrm{m}$ geometric dimension) is even more dramatic. As the calcination temperature is increased from 650 to 700 , and ultimately to $1000^{\circ} \mathrm{C}$, the percentage of particles in the respirable range decreases from 40 to 25 and finally to $10 \%$. Similar changes in particle size are anticipated if existing oxides are fired at high temperature. Increasing the apparent particle size has a beneficial effect on adsorption and on dispersal because adsorbates are removed, the capacity for readsorption is reduced, and the dispersibility/inhalation risk is decreased. High temperature calcination has been avoided in the past because it reduces the chemical reactivity of the oxide for dissolution and fluorination. However, its suitability for direct oxide reduction (DOR) is enhanced. Advanced dissolution techniques using silver (II) catalyzed nitric acid allow easier dissolution of high-fired oxides.

${ }^{39}$ R.E. Felt, presentation to the DOE task force on plutonium storage, Germantown, MD (July 20, 1993). 


\section{Current Storage Practices}

Current plutonium storage practices at DP facilities are summarized in Table 1 . The content of the table and following discussion are based on information presented at the workshop and contained in written responses to DP requests.

Current plutonium storage practices at DOE sites (DP sites and Argonne West) reflect a balance between desire to maintain the metal for programmatic needs and the desire to avoid unnecessary costs and personnel radiation exposures associated with cleaning and repackaging the metal. Surveillance of stored materials is primarily for security and safeguard/SNM material inventory rather than safety reasons. At most sites, the safety inspections involve periodic manual examination of a statistically significant fraction of the storage containers.

This section includes discussions of the containers used for storage of metal and oxide at DOE facilities and provides information on the experience and practice in storing plutonium at those sites. The specific storage procedures used for metal, for oxide from metal corrosion, and for process oxide are described.

\section{III.A. Containers}

Most DOE contractors use low cost containment schemes for the external storage of plutonium in vaults. In most cases this involves the use of taped, slip lid (e.g., Vollrath) cans or crimp-seal (food-pack) cans for the primary containment enclosed by a plastic bag for glove box environment removal. The bagged can is then usually placed in a second metal can (either slip-lid or crimp-seal type) which is placed on the vault shelf. Neither of these schemes may be considered to provide a long-term "hermetic" seal of the material against atmospheric exposure. The food pack cans rely on a latex coating on the lid to provide an initially air-tight seal, but this polymer is subject to radiolytic decay from contact with normal contamination over time. However, the outer container may provide for the necessary air tightness in the event of breakdown of the inner seal, while the inner container will still provide for physical containment of the metal and any generated oxide.

\section{III.B. Metal Storage}

Several DOE facilities presently store plutonium as metal. These include Rocky Flats, Los Alamos National Laboratory, Lawrence Livermore National Laboratory, Savannah River, Argonne National Laboratory-West, and Hanford. Proper storage of the metal, either in a vault-type room or within ventilated glove boxes, focuses on preventing contact of the metal with plastics or other organic materials (e. g., hydrocarbon oils) which are radiolytically decomposed by alpha decay to form hydrogen and other gases.

The use of tape to seal slip-lid containers is probably less reliable than crimp-seal cans because tape does not provide even an initial air-tight seal, and allows for gradual degradation and oxidation of the metal over time. Reaction could result in a mechanical wedging-type rupture of the primary and possibly secondary container. Reduced risk to vault operations personnel from such packaging can be controlled with routine visual and non-destructive (e. g., mass measurement) examinations of stored items and with health physics monitoring of these storage areas for release of radioactive contamination. A history of multi-year storage of such items shows that rupture of containers is rare. 


\section{Table-1. Plutonium storage practices at DP sites.}

$\underline{\mathrm{Y}-12}$ - Minimal quantities (Pu-Be sources and lab solutions)

$\underline{\text { LLNL }}$

- All Pu stored in sealed containers

- Labels and seals checked bimonthly

- Physical inventory of parts and statistical sample of containers

- Inner sealed cans opened if contents suspect

- All inspections in closed glove box or inspection hood (could introduce oxygen into container atmosphere and increase corrosion)

- Procedure for storage area monitoring, cleaning oxides and repackaging

- Over 70\% of inventory has been surveyed, consolidated and repackaged in last 18 months

- No requirement for safety inspections of metallic Pu in sealed containers

- No unsafe storage identified in past inspections

NTS

- Only waste and weapon components

- No procedures

SRS

- SRS-produced buttons packaged in two crimp-sealed, metal food pack cans, with heat sealed plastic around inner can

- SRS metal samples in vials within food pack cans within 5 gallon containers

- Metal from offsite is packaged in two sealed, metal food pack cans

- Confirmatory random sampling of containers checked for contamination, can integrity, SNM and weight gain/loss per standard operating procedure (SOP)

- Bimonthly physical inventory of all containers of process-generated materials (not of containers received from off site) per SOP - check for tamper and mechanical integrity of cans

- Inspections on schedule - latest completed 5/17-18/93

- Substantial amount of material stored from Central Scrap Management Office (CSMO) in sealed shipping containers

- No safety concerns identified

\section{HANFORD}

- Pu stored and inspected in accordance with procedures in vaults and vault-type buildings at PFP

- Material includes metal, oxide, and other residues

- Stored in two mechanically sealed containers (outer food-pack can)

- Containers inspected before and during storage

- Vault 2 inspected visually, vaults 1,3 and 4 monitored remotely - $100 \%$ coverage on a monthly basis for corrosion, dents, holes, bulges, etc., and repackaged in argon atmosphere, if necessary 
Table-1. Plutonium storage practices at DP sites (continued).

\section{LANL (TA-55)}

- Material includes metal, residue metal, oxides, and other residues

- Metal stored in sealed containers in vaults or inert glove boxes

- Swipes of containers and storage area

- No inspection of metal in storage

- Oxidation reaction/contamination incident in February, 1993, due to container with degraded plastic (hydride) opened in hood rather than glove box

- Material repackaging and consolidation plan for future storage relies on high integrity container and storage environment characterization instead of extensive inspections

MOUND

- Metal stored in sealed containers in vaults or inert glove boxes

- Swipes and visual inspections of containers

\section{PANTEX}

- Metal in sealed (welded) pits

- Pits swiped prior to storage in approved containers and regularly monitored for contamination

ITRI

- Very small amount (<10 grams) in approved shipping container

\section{ROCKY FLATS}

$-27 \%$ of metal stored in line, $73 \%$ out of line

$-16 \%$ of oxide stored in line, $84 \%$ out of line

- Various can/plastic/can/carrier combinations (up to three)

- Issues include:

- metal in contact with plastic

- metal in improperly sealed produce cans

- inconsistencies with internal procedure HSP 31.11- reexamining HSP 31.11 to accommodate longer storage rather than time period required for resumption

- a quantity of oxide calcined at low temperature (not stabilized) 
Many sites find it necessary to store plutonium as metal in glove box lines. Since contamination is not a primary concern in this case, attention might be focused on protecting against contact with plastics and other organic materials to prevent hydride formation that may result in sparking. Additionally, such sites should also be clear of other combustibles, such as rags. Experience has shown that the oxidation process can be significantly retarded by cooling the storage environment or dehumidifying the storage atmosphere. A typical glove box atmosphere is either dry air $\left(-40^{\circ} \mathrm{F}\right.$ dew point), reduced oxygen in air ( 3 to $\left.5 \% \mathrm{O}_{2}\right)$, dry nitrogen, or dry argon.

Although the above mentioned packaging methods (slip-fit can with taped lids, heat- or mechanically-sealed plastic bags, crimped food product cans with latex gasket) do not represent unusual hazards, they do not represent optimum methods for the longer-term ( $>5-10$ years) storage of plutonium metal, especially where retrieval of the intact metal is desired. The preference here again is to ensure good protection of the metal against oxidative degradation, either through fully welded containers, metal gasket seals, or at the minimum, double food pack sealing.

Finally, although not predominantly a safety issue, most contractors use plutonium in its metallic form, and the ability to preserve the metal becomes an economic issue as well as a radiation exposure and waste generation issue, since it is undesirable to needlessly reprocess the material from oxide back to metal.

\section{III.C. Oxide Storage}

Throughout the DOE complex during in-process operations, oxides are typically packaged in unsealed (taped) cans. The technical issues regarding reliability and safety are somewhat different than for metal. As with metal, it is strongly advised that the oxide not be directly packaged in plastic or in close proximity to plastic or other organic materials. Under such conditions, hydrogen is generated by the same radiolytic decay process that forms pyrophoric products during metal storage. ${ }^{40}$ It should be emphasized that this radiolytic decay does not produce a sparking hazard in stabilized oxide because stoichiometric oxide does not react with hydrogen.

Unsealed containers do not pressurize because hydrogen is able to escape. If the oxide is stored in sealed cans, the hydrogen gas pressure can result in possible breaching. Further, product hydrogen, when mixed with air, could ignite and act as an initiator for other combustibles. Therefore, mandatory repackaging of stored materials should be reviewed carefully and only undertaken after a risk assessment is completed.

Perhaps the more difficult issues to resolve concerning the appropriate storage of oxide are its radiolytic decay and hygroscopic nature. As discussed above, this effect could lead to generation of pressures sufficient to breach a sealed container, resulting in release of contamination to the immediate area. Interim storage of plutonium oxide is safely accomplished in unsealed containers, such as taped slip-lid cans, but caution should be exercised with food pack cans, which are at best a temporary hermetic seal.

\section{III.D. Thermal Processing Practices at DOE Facilities}

To prevent pressurization in storage containers, plutonium oxides are normally thermally processed prior to storage outside of Zone 1 HVAC systems (e.g., glove box or in-line vault ventilation systems). Plutonium oxides stored within a Zone 1 system may be vented so that radiolytic decomposition will not pressurize the containers. In this section, two sources of oxide are

${ }^{40}$ G. Friedlander, J.W. Kennedy, and J.M. Miller, Nuclear Radiochemistry, 2nd ed., John Wiley and Sons, Inc., New York (1966). 
discussed. The first source is plutonium oxide produced by the corrosion of plutonium metal. The second is oxide produced from chemical processing, (e.g., by calcination of plutonium oxalate or plutonium peroxide precipitates). Each type of oxide has separate properties. Oxides produced by the corrosion of metal may contain small quantities of metal fines and hydrides, and possibly some sub-oxides, and may gain weight when thermally stabilized. Oxides produced by chemical processing contain impurities which can be decomposed by radiolytic processes. Decomposition products are almost always gases which can pressurize a sealed container. Process oxides lose weight during thermal processing. The remaining impurities may consist of moisture, residual anions (oxalate, nitrate etc.), and organic materials which have not been completely removed in the calcination process.

The principles of thermal stabilization are well known. The pyrophoricity of oxides produced from corrosion of plutonium metal has also been investigated. 41 The basic chemistry and properties of these materials are discussed in Section II.A.

The current practices at various DOE sites for storing plutonium metal and oxides were presented at the workshop. A discussion for each site follows:

\section{III.E. Storage Experience at Individual DOE Facilities III.E.1. Rocky Flats Plant}

The Rocky Flats Plant has been the primary source of pyrophoric plutonium incidents in the weapons complex, because of the nature of its mission. Plutonium metal casting produces casting skulls that are pyrophoric. Machining of plutonium metal produces metal chips or turnings which are pyrophoric and oily. Conveyor lines have been used for plutonium storage. Since plutonium pits were the primary plutonium product shipped from Rocky Flats, all other plutonium metal was considered in-process and was not packaged for long-term storage. The current four year production outage has focused attention on the need for improved storage because of the change in Rocky Flats mission.

Ignition of pyrophoric forms of plutonium has resulted in several major fires and explosions at Rocky Flats since its startup in the mid 1950's. All of these fires have been associated with the pyrophoric forms of plutonium such as casting skulls, turnings and metal fines. A major explosion in 1964 was a result of an operator mistakenly believing that carbon tetrachloride would be a good extinguishing agent for burning plutonium machine turnings.

A major fire in Building 776-777 in 1969 was promulgated by the ignition of a briquette of machine turnings stored on a combustible shielding material. The magnitude of the 1969 fire resulted in multiple improvements in fire safety throughout the DOE complex, especially plutonium metal fabrication. The amounts of combustible materials in glove box lines has been minimized. A nitrogen atmosphere with up to $5 \%$ oxygen has been used at Rocky Flats to prevent enclosure fires initiated by ignited plutonium chips. No major fire has occurred in the last 24 years even though pyrophoric chips and turnings have ignited on a frequent basis during production.

Storage of plutonium metal and oxide at Rocky Flats has always been considered temporary. Thus, the containers have not been sealed as at other sites. Storage in slip-lid stainless steel cans with the lid taped has been standard practice. The slip-lid cans are "bagged-out" and tape-sealed in larger produce cans if the material was to be stored outside the zone 1 enclosure system. The current storage situation at Rocky Flats has plutonium metal and oxide stored in and out of enclosure systems. The atmosphere of the enclosures contains approximately $5 \%$ oxygen plus

41J.T. Waber, "Corrosion and Oxidation" in Plutonium Handbook a Guide to the Technology, Vol I and II, ed. O.J. Wick (American Nuclear Society, La Grange Park, IL, 1980) Chapter 6. 
moisture, so that metal corrosion in taped lid cans is a continuing process. The oxide is intermittently brushed from the metal and the metal returned to storage. Plans are now being implemented to improve the storage of metal and oxide in hermetically sealed containers and the overall thermal stabilization of oxide in storage.

Much of the metal in storage at Rocky Flats is packaged not for longer term storage, but for reuse. In some cases, metal is enclosed in plastic, which is then doubly enclosed in metal cans. Previous experience has demonstrated that this method of storage results in severe corrosion of the metal over time. The corrosion products may contain small quantities of metal fines, hydrides, and perhaps sub-oxides. These are reactive and require thermal stabilization. If the corrosion products are not stabilized after removal from the metal, they are considered potentially pyrophoric. In the absence of a stabilization capability during the past four years, the practice has been to store no more than 200 grams of corrosion product in any single container and to place the container on a heat sink equipped with a heat detector head. The bases for this approach are the conservative assumptions that, if the material reacts, it will be an instantaneous reaction, and that there is no heat transfer mechanism for heat removal. In reality, the oxidation of the corrosion products normally occurs at a slow rate with the in-leakage of air and heat transfer mechanisms do exist that, if considered, would allow storage of larger quantities of such materials. Rocky Flats has the capability to thermally stabilize the products from corrosion of plutonium metal. Rocky Flats has believed that there is a potential problem with storage of these products without stabilization.

All process oxide stored in sealed containers is calcined to meet loss on ignition (LOI) requirements. Oxides which do not meet this test are stored in vented containers. Rocky Flats has the capability to calcine oxides and to thermally remove adsorbates from process oxides. Some of these oxides have not been thermally stabilized and remain in-line in vented containers.

\section{III.E.2. Los Alamos National Laboratory}

Los Alamos National Laboratory (LANL) has a limited quantity of plutonium which is handled and stored as a result of laboratory-scale operations. Continuous laboratory operation has precluded production shutdowns common with other facilities such as Rocky Flats, Hanford, and the Savannah River Site. Long-term storage has not been a problem and pyrophoric materials have been processed as they were produced.

LANL takes no special precautions for storing or stabilizing oxide produced from the corrosion of plutonium metal. They do not consider the corrosion products to be a safety problem. They recognize that the oxide product may contain some metal fines and hydrides, but experimental work has shown that these are oxidized rather readily to a stable oxide. They have recognized that when oxidized, hydrided, or corroded metal is exposed to an air atmosphere, an exothermic reaction may occur.

Oxide product from chemical processing is usually stored in vented containers, because of the difficulty in preparing material which will be stable during storage. The primary concern is that plutonium oxide has a high affinity for adsorption of water vapor. Even though the moisture can be removed by calcining at high temperatures, it can be re-adsorb during the packaging operations. A qualified oxide suitable for storage in a sealed container is defined as a material that has been fully characterized, meets the loss on ignition test, and is subsequently handled and packaged in an atmosphere which precludes moisture adsorption. 


\section{III.E.3. Hanford}

Plutonium pit fabrication was performed at Hanford until 1966. Problems associated with metal turnings and fines were common, although no major fire occurred. Since 1966, plutonium operations have been limited to aqueous processing and metal button and oxide production. Storage of plutonium metal and oxide has resulted in several breeches of containment causing contamination spread within storage vaults. The storage of calcined plutonium nitrate containing residual nitrate has caused pressurization and rupture of storage cans. Hanford uses food-pack cans for metal and oxide storage. Seal failure of food pack cans has required repackaging of several metal storage containers every year.

In the Hanford storage vaults, an automated system for monitoring temperature and pressurization is used. Details of this system (the Vault Safety and Inventory System, VSIS) are available elsewhere. ${ }^{42}$ In the VSIS system, vault instrumentation including transducers, sensors, multiplexors, analog to digital converters, the communications network, and the SNM storage receptacles are collectively referred to as Canister Monitoring Units (CMUs). The CMU measures canister presence, bulge, temperature, and identification. ${ }^{43}$ Pressure data is recorded several times per second, while the remaining inventory information is queried at a rate of $600 \mathrm{items} / \mathrm{minute}$. The storage pedestals are equipped with strain gauges which detect any significant increase in storage weight.

Although corrosion of plutonium metal is recognized, no special procedures are in place to remove corrosion products. The corrosion products formed are considered to not be a safety problem. In recent years, they have had no problems with containers storing metal.

The chemical stability of oxide produced from chemical processing is of concern. Hanford has specified that the volatile content must be $1 \%$ or less from loss on ignition at $450^{\circ} \mathrm{C}$ for 2 hours. An additional limit is a maximum thermal decay of 15 watts. Plutonium oxide which has been properly stabilized is not considered to be a safety problem while in storage.

\section{III.E.4. Savannah River Site}

Handling of plutonium metal at the Savannah River Site (SRS) has involved primarily metal buttons $(2 \mathrm{~kg}$ ) and the scrap associated with metal production. The scrap was immediately recycled to the canyon dissolvers to avoid storage problems and also to recycle the plutonium. Storage and metal handling problems have not occurred at SRS.

Although corrosion of plutonium metal is recognized, there are no special procedures in place to remove corrosion products. The corrosion products are not considered a safety problem.

The chemical stability of oxide produced from chemical processing is of concern. An LOI test is used for assuring stability of stored oxide. At the SRS, there are a number of containers of plutonium residues which were received under the sponsorship of the Central Scrap Management Office (CSMO). These residues remain in the shipping containers in which they were received. SRS assumes that the materials are stable. The materials have not been characterized by SRS.

${ }^{42}$ N.J. Downey, "Vault Safety and Inventory System Users Manual," Westinghouse Hanford Company, Richland, WA, WHC-SD-339-SDR-004 (December 1989).

${ }^{43}$ C.C. Scaief III and N.J. Downey, "Microcomputer and CMU Electronics Equipment Manual," Rockwell Hanford Operations, Richland, WA, SD-CP-EQM-009 (January 1986). 


\section{III.E.5. Argonne National Laboratory}

Argonne National Laboratory has not used plutonium of any magnitude at its facilities near Chicago, nlinois. Research and development involving plutonium have been limited to ArgonneWest at the Idaho National Engineering Laboratory near Idaho Falls, Idaho. The Zero Power Physics Reactor (ZPPR) used encapsulated $\mathrm{Pu}-\mathrm{U}-\mathrm{M}$-M alloy fuel plates which are now in storage. No difficulty in handling or storing this material has been encountered. Fuel cycle R\&D with pyrochemical reprocessing of reactor fuel has utilized plutonium, but not in a form that was pyrophoric. Storage of metal and oxide has never been a source of problems.

Material is stored in an argon atmosphere containing $<50 \mathrm{ppm}$ oxygen and $<50 \mathrm{ppm}$ moisture. Inspections are driven by MC\&A requirements. Oxide corrosion product from plutonium metal is not considered a problem. Powder may be removed from the metal by brushing, however, no stabilization is performed. The oxide is not considered a saiety concern. Other oxides are stored dry, and no problems with pressurization have been encountered.

ANL-W uses some special design cans for storage of oxide and metal. They include the Gavin can for storage of metal and oxide, and the Duncan container used for storage of fuel. The Gavin can consists of two elastomer-sealed vessels nested one inside the other. Three bolts compress the lid against the ethylene propylene o-ring which provides a leak-tight seal. The Duncan container is essentially a closed pipe with a removable, compression seal. A special end-cap fitting allows leak checking of the container and associated welds.

\section{III.F. Applicable DOE Orders. III.F.1. DOE Order $\mathbf{5 4 8 0 . 5}$}

Current DOE requirements for the storage of plutonium are presented in DOE Order 5480.5, SAFETY OF NUCLEAR FACILITIES, 9-23-86. In paragraph 8, BASIC REQUIREMENTS, the requirements for all nuclear facilities and operations are specified as are the requirements for nuclear criticality safety in paragraphs 11 and 12.

Paragraph 13 covers the requirements for the safe storage of unirradiated fissionable materials. Theses requirements do not apply to:

- When materials are in-process as part of production, analytical and developmental procedures (including in-process storage), or transport operations.

-When an assembly cell is used for assembly and/or storage of weapons components made of these materials.

-When the number of packages of materials prepared for shipment is limited in accordance with the requirements of DOE 5480.3 (SAFETY REQUIREMENTS FOR THE PACKAGING AND TRANSPORTATION OF HAZARDOUS MATERIALS. HAZARDOUS SUBSTANCES AND HAZARDOUS WASTES).

- Radioactive waste storage or disposal facilities. 
The operating requirements are given in subparagraph $b$. Operating Requirements for Storage and are summarized below:

(1) Non-essential combustible materials shall not be stored in the storage area.

(2) All unessential extraneous operations and materials (non-nuclear materials, equipment) shall be excluded from the storage area.

(3) Documented periodic inspections, tests and maintenance shall be performed on essential safety components (e.g. criticality control, fire detection, radiation monitoring, etc.).

(4) Limits for criticality safety shall be posted in conspicuous places near the storage area.

(5) Signs or other appropriate devices shall be used at strategic location in or around the area to provide instructions for:

(a) interpretation of, and response to alarms;

(b) evacuation routes; and,

(c) fighting fires.

(6) In conjunction with the site emergency plan, develop a fire fighting plan that includes use of emergency equipment and exercise through periodic drills.

(7) Provide equipment (auxiliary fire fighting, self-contained breathing apparatus, and protective clothing) for manual fire suppression.

(8) Excess fissionable materials shall not be construed to be "In-Process" to circumvent the requirements of this paragraph.

(9) Fissionable materials may be stored in shipping containers to enhance safety but not to negate the requirements of this paragraph.

(10) All materials shall be stored in racks or equivalent equipment (such as birdcages) capable of securely locating stored materials to prevent displacement, to assure spacing control, and to meet design for safety under operational and credible accident conditions. Floor storage within the storage facility will be permitted only where control of location and other safety requirements (equivalent to those of racks) are inherently provided by the individual containers and their restraints.

(11) All pyrophoric materials shall be put into a safe form prior to storage or stored in approved containers that will not permit spontaneous ignition or dispersal. Other dispersible materials must be stored in approved storage containers.

(12) Containers shall be marked or coded for type of material, amount, enrichment (or pertinent data on isotopic composition), and external radiation level. Must be securely closed.

(13) Container design shall be appropriate for form of material stored. Criteria for container integrity shall be developed for required safety analysis and verification of performance of container for the criteria by periodic inspection. Containers involving any significant gas buildup, automatic pressure relief or other venting should be designed to assure that no personnel exposure to any released toxic material will occur under normal storage conditions or, insofar as practical, under accident conditions. Such venting must not permit spread of contamination. 
(14) Plutonium or U-233 bearing or contaminated material shall be packaged in a closed metal container. Combustibles within the container shall be minimized.

(15) Plutonium storage facilities and containers shall be monitored and checked periodically to assure continued integrity of containment. When required by form or hazard potential of the stored material, procedures shall be developed to detect contamination or loss of primary containment upon entering the plutonium storage facility.

(16) Plutonium containers in which gas buildup can occur shall be designed to prevent leakage of gas over the maximum storage period or vented to prevent an accumulation of explosive gases; however, such venting must not permit the spread of contamination. [Similar to (13)]

(17) Criteria, such as internal and external corrosion rate for determining the suitability of the plutonium container, shall be developed and set forth in writing. All containers shall be periodically inspected against the criteria. The time between inspections may vary depending upon the container quality and type. [Similar to (13)]

(18) Provisions shall be made in a plutonium storage facility to assure necessary and adequate heat removal for plutonium containers as established by the safety assessment.

Additional requirements are specified for multipurpose facilities (storage and processing) in section c. (Multipurpose Facility (Processing and Storage):

- definition of in-process material shall be established, approved, and maintained thereafter until approved changes are affected.

- shall designate which materials may be termed "in-process" and which may not.

- promptly placed materials in excess of in-process requirements into approved storage facilities.

\section{III.F.2. DOE Order 5480.3}

Requirements for packaging and transport of fissionable materials are covered in DOE Order 5480.3 - SAFETY REQUIREMENTS FOR THE PACKAGING AND TRANSPORT OF HAZARDOUS MATERIALS, HAZARDOUS SUBSTANCES AND HAZARDOUS WASTES, 7-9-85.

Fissile materials are defined in paragraph 5, DEFINITIONS, as uranium-233, uranium-235, plutonium-238, plutonium-239, plutonium-241, neptunium-237, and curium-244. Fissile material packages for shipping are divided into three classes:

Fissile Class I. Packages that may be transported in unlimited numbers and in any arrangement and that require no nuclear criticality safety controls during transportation.

Fissile Class II. Packages that may be transported in any arrangement but in numbers that do not exceed a transport index of 50. (Transport index is defined in subparagraph 0 . as "The number placed upon a package to designate the degree of control to be exercised by the carrier during transport. The transport index of Fissile Class II packages is calculated by dividing the number 50 by the number of such Fissile Class II packages that may be transported together as determined under the limitations of 10 CFR 71".) 
Fissile Class III. Shipments of packages that do not meet the requirements for Fissile Class I or II and that are controlled in transportation by special arrangements between the shipper and the carrier to provide criticality safety.

Most of the stored materials considered in this report fall in Fissile Class III.

Requirements are specified in paragraph 7, REOUIREMENTS. Requirements for plutonium are covered in subparagraph $b$, Special Packaging Requirements for Plutonium and Plutonium Bearing Waste. The first 2 items concern certification for transport and packages. Item (3) states "Plutonium package requirements for any surface mode of transportation".

(a) Plutonium in excess of 20 Curies per package must be shipped as a solid.

(b) Plutonium in excess of 20 Curies per package must be packaged in a separate inner container placed within outer packaging that meets the requirements of a Type B package for material in normal form. In addition, the following test must be performed on the package design:

(1) If the entire package is subjected to the design tests specified in paragraph 11 , "Normal Conditions of Transport," the separate inner container must restrict the loss of plutonium to no more than $10^{-6} \mathrm{~A}_{2}$ /hour.

(2) If the entire package is subjected to the design tests specified in paragraph 12 , "Hypothetical Accident Conditions," the separate inner container must restrict the loss of plutonium to not more than the $\mathrm{A}_{2}$ quantity in 1 week.

The $A_{1}$ and $A_{2}$ values for plutonium isotopes are excepted from Table 2 (IAEA, 1990) below:

Table 2. $A_{1}$ and $A_{2}$ values for radionuclides.

\begin{tabular}{llllll}
\hline $\begin{array}{l}\text { Symbol of } \\
\text { radionuclide }\end{array}$ & $\begin{array}{l}\text { Element and atomic } \\
\text { number }\end{array}$ & $\mathrm{A}_{1}$ (TBq) & $\begin{array}{l}\mathrm{A}_{1}(\mathrm{Ci}) \\
\text { (approx.) }\end{array}$ & $\mathrm{A}_{2}(\mathrm{TBq})$ & $\begin{array}{l}\mathrm{A}_{2}(\mathrm{Ci}) \\
(\text { approx. }\end{array}$ \\
\hline${ }^{236} \mathrm{Pu}$ & Plutonium (94) & 7 & 100 & $7 \times 10^{-4}$ & $1 \times 10^{-2}$ \\
${ }^{237} \mathrm{Pu}$ & 20 & 500 & 20 & 500 \\
${ }^{238} \mathrm{Pu}$ & & 2 & 50 & $2 \times 10^{-4}$ & $5 \times 10^{-3}$ \\
${ }^{239} \mathrm{Pu}$ & 2 & 50 & $2 \times 10^{-4}$ & $5 \times 10^{-3}$ \\
${ }^{240} \mathrm{Pu}$ & 2 & 50 & $2 \times 10^{-4}$ & $5 \times 10^{-3}$ \\
${ }^{241} \mathrm{Pu}$ & & 40 & 1,000 & $1 \times 10^{-2}$ & $2 \times 10^{-1}$ \\
${ }^{242 \mathrm{Pu}}$ & & 2 & 50 & $2 \times 10^{-4}$ & $5 \times 10^{-3}$ \\
${ }^{243} \mathrm{Pu}(\mathrm{b})$ & & 0.3 & 8 & $2 \times 10^{-4}$ & $5 \times 10^{-3}$
\end{tabular}

Paragraph $7 \mathrm{~b}(4)$ states "Solid plutonium in excess of 20 Curies per package in the following forms is not subject to the requirements of paragraph $7 \mathrm{~b}(3)$. Item (b) is Metal or metal alloy.

Other relevant paragraph for outer packages are:

Paragraph 8. PACKAGE STANDARDS.

Paragraph 11. NORMAL CONDITIONS OF TRANSPORT

Paragraph 12. HYPOTHETICAL ACCIDENT CONDITIONS 


\section{Advanced Storage Concepts}

\section{IV.A. Containers}

A definite improvement in the use of current slip-lid/food pack cans to store plutonium metal could be obtained by eliminating air from the package atmosphere. This could be accomplished by packaging the metal in helium followed by routine leak testing before and during storage. A true hermetic seal, either in a metal gasket-sealed vessel or an all welded vessel would provide extra assurance in packaging. Additional confidence is gained from the fact metal has been stored in sealed pits for more than 30 years in the stockpile without incident. Optimally, the gasket-sealed vessel would be QAcertified and leak-tested prior to use, whereas the all-welded vessels would be leak-test certified after final sealing. Also, the optimum atmosphere in the storage container should be a mixture of helium with a mildly oxidizing gas, but dry or any inert fill would be suitable if hermetic sealing is assured.

LANL is currently developing a hermetically sealed package for retrievable storage of metal which allows storage in a dry inert atmosphere and prevents corrosion for both short duration and long periods of time (10 years or more). Figures 3 and 4 show the concepts for these containers. The principal difference between these concepts is the exclusion of organic bagging from the long-term container. Implementation of this concept (figure 4) will require development of specialized packaging and handling procedures which might include bagless transfer or decontamination techniques.

As with metal, if the use of a hermetic container such as a fully welded vessel or a metal gasket-sealed container is contemplated for storage of oxide, consideration must be given to quantifying the amount of residual water left on the oxide, (e.g. certified LOI evaluations) so that the container is able to accommodate the maximum possible pressure accumulation due to desorption or radiolysis. Alternative approaches for storing uncharacterized oxide include the use of sealed storage cans with metal frit filters which would allow for atmospheric pressure equilibration. Such frits have been used for prevention of contamination migration in various weapons program applications in the past. Since substoichiometric oxide or unreacted metal may be present in uncharacterized oxide, thermal stabilization is recommended to ensure that the material is completely converted to the dioxide. Conversions of this type may be accomplished by roasting at modest temperatures $\left(300\right.$ to $\left.500^{\circ} \mathrm{C}\right)$ in air. If other plutonium compounds (e.g., nitrates or sulfates) are present, higher temperatures may be necessary.

LANL is also developing new containers for the storage of oxide. For stabilized, unqualified oxide, they are developing a vented container to allow for release of gases from radiolytic decomposition. Figure 5 shows the concept for this container. For stabilized, qualified oxide, LANL is developing a sealed container in which the oxide is stored in an inert atmosphere. Figure 6 shows a concept for this vessel. As with the long-term metal storage container, bagless transfer or other specialized handling will be required to implement this concept.

Additional improvements allow for improved labeling of vault stored items, including internal packaging details, and appropriately integrated surveillance and inspections to satisfy not only MC\&A, but also container integrity and contamination detection. For long-term ( $>5$ yrs.) storage scenarios, only fully stabilized and loss-on-ignition qualified oxide should be stored and use of hermetically sealed containers is recommended. At present, most contractors storing metal and oxide rely on routine MC\&A-based inspection and audits to provide integrity assurance of vault items. In addition, Zone 2 type rooms such as storage vaults receive routine health physics surveys for contaminations. In combination, these provide a reasonable minimum surveillance activity. Balanced MC\&A surveillance, including weight measurements, automated room contamination monitoring, and random visual and perhaps radiographic package inspections are considered the optimum oversight of these items. 
All containers 6" maximum diameter, 12" maximum height, packaged in inert atmosphere.

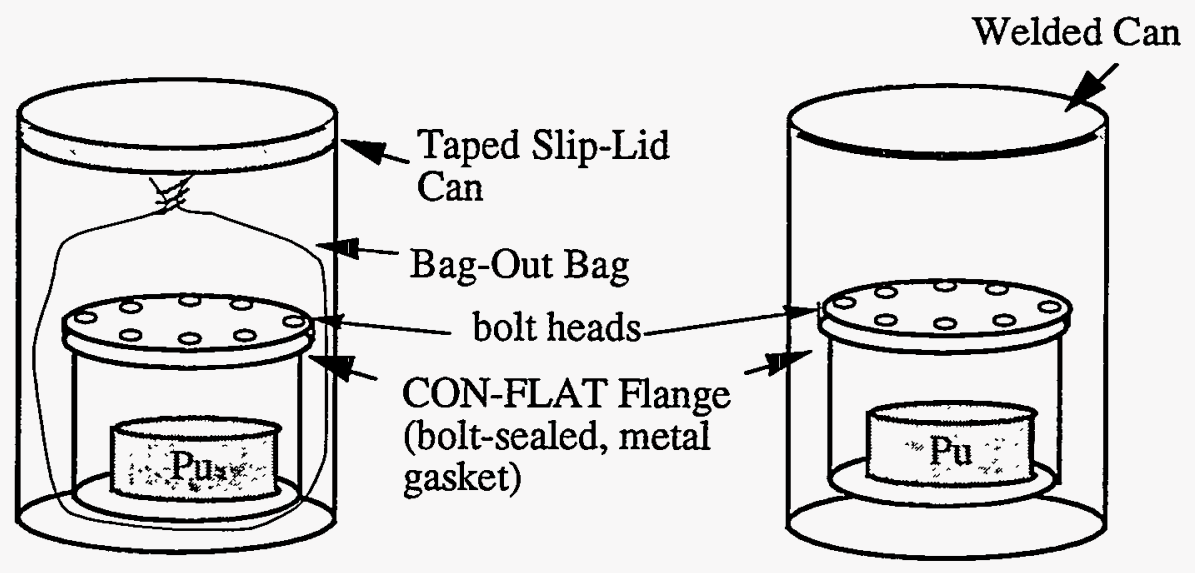

Figure 3. Plutonium metal storage container, short-term duration.

Figure 4. Plutonium metal storage container, intermediate to long-term duration.

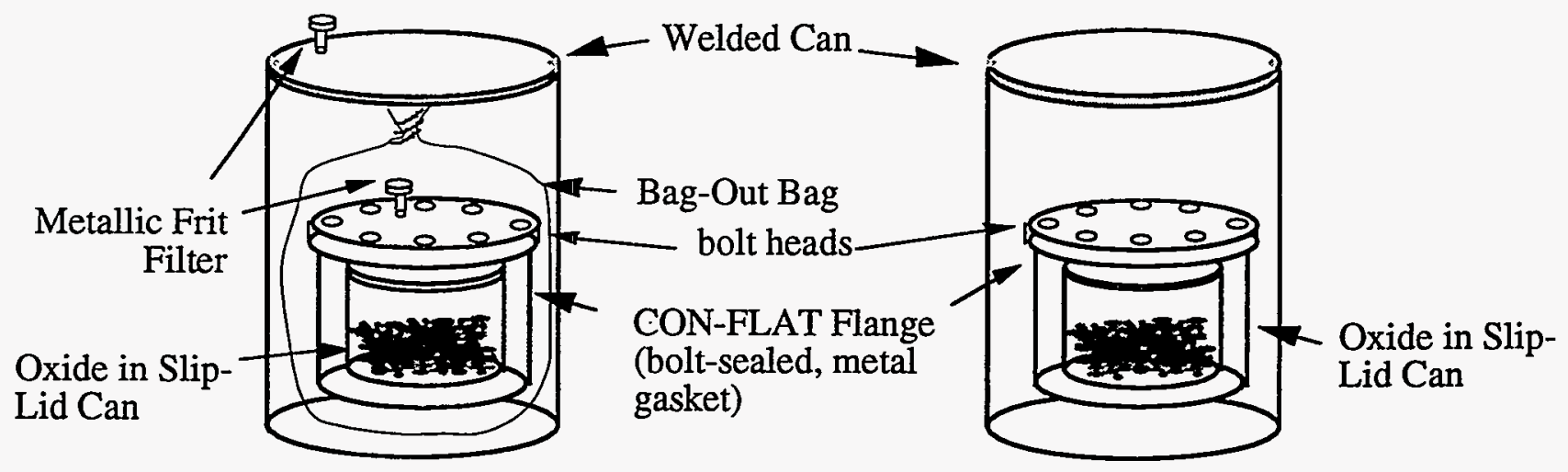

Figure 5. Storage container for stabilized, unqualified oxide, short-term duration.
Figure 6. Storage container for qualified oxide, short-term, intermediate, and long-term duration. 
The quantity of material stored in each individual container will be determined by criticality safety concerns. Historically, these limits have varied from an extremely conservative 3 kilograms to as much as 6 kilograms of Pu metal per vessel. Similar quantities of oxide will likely be permitted per container. Recent limits near 4.5 kilograms per container have been established.

\section{IV.B. Material Form}

In the absence of a facility fire hazard, the dominant hazard from storage of plutonium arises from the dispersibility of the oxide powder. Some concepts are discussed below for reducing this potential hazard. They include converting the oxide to a stable physical form with low dispersibility and preventing its generation from the metal. The benefits of these concepts would need to be weighed against the costs of implementing them, including the potentially large doses to workers and large amounts of generated wastes resulting from processing to various forms.

\section{IV.B.1. Pelletizing}

Plutonium oxide can be converted into a mechanically stable form with reduced dispersibility by sintering it into a ceramic form(e.g., pellets) under pressure. Oxide powder is vacuum degassed, milled or ground to the appropriate particle size, placed in a die, and simultaneously compressed and heated at $50-60 \mathrm{kpsi}$ at $1,500^{\circ} \mathrm{C}$ for an appropriate period of time. ${ }^{44}$ The resulting pellets are packaged in a hermetically sealed container under an atmosphere of inert gas or dry air.

Storage of sintered pellets in hermetically sealed containers would ensure their long-term stability. However, data for ${ }^{238} \mathrm{Pu}$ oxide indicate that degradation of the pellets may occur with time as a result of helium production from alpha decay. ${ }^{45}$ The ${ }^{238} \mathrm{Pu}$ oxide pellets were found to swell and become somewhat friable and, under some circumstances, were highly strained. Though the helium production rate in weapons grade plutonium is lower than that for ${ }^{238} \mathrm{Pu}$ by a factor of nearly 300 because of the difference in decay rates, the significance of this effect to long-term storage of the sintered material would need to be assessed.

Sintered pellets may fragment under crush-impact forces when new and may become more susceptible to fragmentation with age. Accordingly, they might require protection from forces present during collapse of a storage facility. Issues of through-put, waste generation and personnel exposure to radiation must be considered and weighed against the advantage of pelletizing. Pressing is a time-consuming operation and pelletizing of a large quantity of oxide may not be achievable on a reasonable time scale without investment in facilities and equipment. The existing capability for converting plutonium oxide to sintered pellets at DOE facilities is described along with process conditions and equipment requirements in Appendix B.

\section{IV.B.2. Sintering}

As discussed in Section II.G, calcining of oxide powder at a temperature of $950-1,000^{\circ} \mathrm{C}$ for one hour affords certain advantages for mitigating the dispersal risk. In addition to increasing the effective dimension of oxide particles, thermal processing of this type simultaneously removes adsorbates. As such, the risk and degree of potential pressurization is reduced and the

${ }^{44}$ R.N.R. Mulford and B.A. Mueller, "Measurements of Helium Release from Materials Containing ${ }^{238} \mathrm{PuO}_{2}$," US DOE Report, Los Alamos, NM, LA-5215 (July 1973).

45B.A. Mueller, D.D. Rohr, and R.N.R. Mulford, "Helium Release and Microstructural Changes in ${ }^{238} \mathrm{PuO}_{2}$," US DOE Report, Los Alamos, NM, LA-5524 (April 1974). 
qualifications for certification are met. Equipment and basic techniques currently used for calcination at lower temperatures can normally be used up to $1100-1200^{\circ} \mathrm{C}$ and could be readily implemented at most facilities with minimal development effort.

\section{IV.B.3. Reduction of Oxide to Metal}

Plutonium oxide can also be converted to a mechanically stable form with reduced dispersibility by reduction to the metal. The conditions and equipment for direct oxide reduction (DOR) are widely available and capable of handling necessary throughput.

In comparison to normal process oxide, the dispersibility risk is low if metal is exposed to the atmosphere by a breach of containment or if the incident involves both a breach and a fire. Experience with typical ( $4 \mathrm{~kg}, 7 \mathrm{~cm}$ diameter) castings of unalloyed metal shows that less than $100 \mathrm{~g}$ of oxide forms over a period of one year. The maximum oxidation rate calculated on the basis of this observation is $1 \times 10^{-4} \mathrm{~g} \mathrm{PuO}_{2} / \mathrm{g} \mathrm{Pu}$ day. At this rate, the amount of dispersible oxide available after exposure of a 4-kilogram casting to air for ten days is a thousand-fold less than for process oxide and is equal to the dispersible quantity formed if the casting had burned immediately in a fire.

The reduction in dispersibility risk by formation of metal is substantial, but the disadvantages of worker radiation exposure and waste generation during processing must also be considered.

\section{IV.B.4. Alloying or Coating of Plutonium Metal to Reduce Corrosion}

Addition of certain elements to metallic plutonium can alter the room-temperature corrosion rate. Gallium-containing alloys show a reduced corrosion rate at temperatures below $250^{\circ} \mathrm{C}$ (Section II.A.). However, the corrosion rates of alloyed and unalloyed material converge at elevated temperatures. Addition of other elements can increase the plutonium ignition temperature slightly. For example, plutonium-aluminum alloys show an ignition temperature in the range of 575$600{ }^{\circ} \mathrm{C}$, compared to $475-500{ }^{\circ} \mathrm{C}$ for unalloyed material. 46 The advantages of alloying plutonium to either slightly decrease the low-temperature corrosion behavior or to slightly increase the ignition temperature must be carefully considered. Other methods may be available to mitigate corrosion problems such as storing plutonium in certified, sealed containers.

Coating plutonium with various materials has been investigated to mitigate dispersal and corrosion hazards. If great care is taken, pinhole-free nickel coatings obtained by chemical vapor deposition of nickel tetracarbonyl can be prepared. Attempts to prepare similar, defect-free coatings with other elements have been largely unsuccessful. Further, routine preparation of acceptable nickel coatings has thus far proven difficult. There is no current capability to produce coatings of necessary quality within the DOE complex.

\section{IV.C. Complex-21 Criteria}

Efforts under way to evaluate storage needs for Complex-21 storage of plutonium metal and oxide are systems-level oriented. Material characterization, qualification, containerization, facility superstructure, and infrastructure considerations are integrated. The storage facility, to be colocated with the plutonium manufacturing and processing facility, is conceptually designed to accommodate items which would be remotely placed and accessed by means of unmanned

46J.G. Schnizlein and D.F. Fischer, J. Electrochem. Soc., 115 (1968) 462. 
vehicles. This building would accept plutonium in the form of pits, metal, oxide, and stable compounds. The Complex-21 facility is intended to store plutonium forms in a stable manner for up to 50 years. Interim storage by contractors must address periods of at least 7 to 15 years, the time-frame between now and when Complex-21 is prepared to accept these materials.

Currently, the plutonium storage facility is expected to become operational in 2001 . The storage facility is envisioned to initially contain 40,000 storage positions, with a capability to receive 6,000 pits and 1,000 other containers per year. The initial shipping capability is estimated to be 1,000 containers per year with the provision to convert receiving to shipping capacity at a later date.

Requirements for Complex-21 structure, containment, material, packaging, and automation are summarized below.

\section{General requirements:}

- Storage container is designed for dual use as a primary containment vessel for both shipping and long-term storage.

\section{Structural requirements:}

- Vessel meets the requirements of the ASME Boiler and Pressure Vessel Code as specified by UCID-21218, NUREG/CR-3019 and NUREG/CR-3854

- Vessel capable of opening without damage to or expelling of inner contents.

-Vessel capable of welding closure without damage to inner contents.

-Vessel capable of being reused after being opened one time.

- Resealed vessel identical in size to original vessel within original fabrication tolerances.

- Minimum design life of 50 years with no routine maintenance.

- Vessel fabricated of material to provide a corrosion resistant containment boundary.

- Vessel meets storage requirements after the following normal occurrences:

$-4^{\prime}$ drop

-2 ' crush with primary containment vessels interacting (heaviest vessel interaction)

- vehicle vibration

- handling shock

- compression weight of 5 primary containment vessels

- Vessel remains leak tight as defined by ANSI N14.5 after the following one time occurrences:

- 30' free drop (maximum vault ceiling height)

- 30' crush with primary containment vessels interacting (heaviest vessel interaction)

- vehicle crash as defined in safety analysis report (SARP)

- puncture as described in safety analysis report (SARP) 


\section{Containment Requirements:}

- Provisions provided for purge and backfill.

- Vessel can be resealed to original integrity after gas sampling operation is complete.

- Nondestructive examination of resealed vessel is possible to determine integrity of resealed vessel.

- Sealed vessel tests leak tight as defined by ANSI N14.5.

\section{Design Temperatures and Pressures:}

- Oxide/metal container currently designed for 1,000 psig internal at $204{ }^{\circ} \mathrm{C}$ for long-term storage. An internal design pressure of $50 \mathrm{psig}$ at $204^{\circ} \mathrm{C}$ is to be used for testing and certification as a primary containment vessel for shipping.

- Pit container designed for $100 \mathrm{psig}$ internal pressure at $204^{\circ} \mathrm{C}$ for long-term storage. An internal design pressure of 15 psig at $204^{\circ} \mathrm{C}$ is to be used for testing and certification as a primary containment vessel for shipping.

- Oxide/metal container and pit container designed for 25 psig external pressure for shipping and storage.

\section{Dimensional Requirements:}

- The pit container meets the following dimensional requirements:

- Minimum internal height of $18.5^{\prime \prime}$

- Maximum external height of $23^{\prime \prime}$ for assembled storage package

- Minimum I.D. of 13"

- The oxide/metal container meets the following dimensional requirements (based on single containment):

- Maximum I.D. of 5-1/4"

- Maximum O.D. of 6"

- Maximum external height of $17^{\prime \prime}$ for vessel as a shipping container

- Maximum external height of 23 " for assembled storage package

- All exterior surfaces of the vessel shall be equal to or better than a number 4 mill finish.

\section{Packing Requirements:}

- All packing materials non combustible per NFPA.

- All packing materials non organic.

- Steady state storage temperature of pit surface not to exceed $60^{\circ} \mathrm{C}$.

-Vessel loaded with an internal atmosphere to be specified.

- Oxide/metal container capable of holding $4.5 \mathrm{~kg}$ of Pu as oxide with 2.5 liters of free volume. Free volume includes space interior to oxide container. 
- Vessel meets requirements of 10 CFR 71, 49 CFR 173, and DOE 5480.3.

- Vessel provided with all welded closures and ports.

\section{Automation Requirements:}

- Container design compatible with automatic handling equipment.

- Bar code for identification and accountability placed on container for remote handling by robot or automatic guided vehicle.

- Bar code permanent (i.e., life expectancy of 50 years).

- Surface of container uniform in color except for vision targets.

- Vision targets have a permanent high contrast color relative to container.

- Accessibility provided for in situ material control and accountability (MC\&A) measurements.

- Self locating interfaces for mating parts.

- Minimize alignment and orientation constraints for assembly interfaces.

As of this time, ${ }^{238} \mathrm{Pu}$ will be excluded from the storage facility. The presence of ${ }^{238} \mathrm{Pu}$ would require water in the vault area. However, water is currently excluded because of criticality safety concerns.

Because of the vault design concept, all primary containers will qualify for dual use in storage and shipping, and will provide for direct NDA measurements. This degree of specialization will almost certainly mean that materials and containers currently existing in the complex will not meet the acceptance criteria and will likely require repackaging before shipment to the Complex-21 facility. This requirement could result in costly duplication of extensive repackaging facilities at each of the contractor sites. It may be more cost effective to establish the final repackaging capability at the ultimate storage site and only require individual contractors to package to the minimum standards required for shipment to the Complex 21 facility.

The present concept requires that materials be stabilized, characterized, and certified prior to acceptance at the storage facility, and oxide/metal be packaged in an inner container devoid of plastics, elastomers, tape, etc., and hermetically sealed in a primary containment vessel by the shipper. The packaging will be suitable for direct vault-location storage of the primary container and will fully meet pressure vessel design requirements per American Society of Mechanical Engineers Boiler \& Pressure Vessel Code, Sec. IIII. 


\section{Hazard Analysis}

A comprehensive hazard analysis is essential to ensure that all significant safety issues are addressed. Indeed, recent workshops sponsored by DP and this report itself are intended to identify any potential safety issues which are not addressed in DOE DP storage operations. This section presents a brief hazards analysis that attempts to bound the risks from practices used throughout the DOE weapons complex. In general, conclusions are presented in this section regarding the severity and probability of various hazards while accompanying relevant calculations may be found in appendices to this report. Much of the material contained in this chapter expands upon information presented in Section II of this report. This duplication arises from the desire to emphasize those material properties of $\mathrm{Pu}$ and $\mathrm{PuO}_{2}$ which are important in a credible hazards analysis.

\section{V.A. Hazard Identification}

The scope of this analysis is limited to storage of plutonium metal and plutonium oxide. Each of these materials falls into two general categories. For metals, a basic distinction is whether the material is alloyed or not. Certain alloys (such as Pu-rich gallium material) exhibit markedly different corrosion behavior at room temperature when compared to unalloyed, $\alpha$-phase material (though corrosion of all common alloys converges to the same rate at elevated temperatures). As such, the chemical reactivity of metallic forms is dependent on chemical composition. However, most other relevant physical properties are similar for metallic forms of plutonium, including densities, surface areas, melting points, etc.

For oxides, the most basic distinction is whether the oxide is relatively free of adsorbed species or has adsorbates that might radiolytically, chemically, or thermally decompose and thus generate reactive, corrosive, or pressure-generating species. In addition, the composition of the oxide may present a hazard if substoichiometric material or unreacted anions (nitrate, oxalate, etc.) are present. The presence of such material is largely dependent on the process and storage history of the oxide. As outlined in Section II, certain physical properties of plutonium oxide are highly variable and depend on the particular conditions in which it was made. The surface area and particle size distribution of oxide (physical properties which directly influence the radiolytic reactivity and dispersibility of the material) are strongly dependent on the formation technique. In general, two categories of oxide are cited: 1) "certified" or "qualified" oxide in which the recent process condition and storage history are known or loss-on-ignition standards satisfied and the presence of foreign contaminants (adsorbates, anions) has been minimized and quantified; and 2) "uncharacterized" oxide in which the above conditions are not met. The majority of oxide possessed by the complex is uncharacterized. Conversion of material to "certified" oxide frequently involves a calcination process in which material is exposed to an oxidizing environment at elevated temperatures (e.g., bakeout at $1,000^{\circ} \mathrm{C}$ for 1 hour in air, see Section II).

The spectrum of storage conditions and the severity of the storage environment can be characterized by three factors: (1) the material form, (2) the preparation and certification of the form for storage, and (3) the storage container, packaging, and environment.

For metal, the primary concern centers on corrosion reactions with gases such as oxygen and hydrogen. Potential hazards from such corrosion include ignition of the material in an oxidizing environment, formation of dispersible and/or pyrophoric products, and mechanical breach of a storage container as a result of volumetric expansion during reaction. Note that gas-phase pressurization of the storage environment is not a credible hazard since the stored metal itself serves to getter any potential pressurizing species. An additional potential concern in metal storage involves the reaction of molten plutonium with the storage container itself. The products of the reaction between $\mathrm{Pu}$ and container materials such as $\mathrm{Fe}$ or $\mathrm{Ni}$ are low melting compounds (e.g., 
$\mathrm{Pu}_{6} \mathrm{Fe}$ ) or eutectics. However, the formation of these compounds appears to be controlled by other factors such as the reduced temperature at the molten $\mathrm{Pu} / \mathrm{metal}$ interface or the absence of other necessary elements which prevents eutectic formation. Further, at lower temperatures (and during ambient storage), these eutectic formation reactions are not considered a hazard since the rates are extremely slow as a consequence of the limited solid/solid diffusion between the reacting materials. As such, the possibility of container breach due to eutectic formation is considered negligible.

For storage of oxide, corrosion is a lesser concern; but radiolysis, chemical reaction, or desorption of adsorbates (e.g., water) and radiolytic decay of organic materials (e.g., plastic bagging, sealing tape, or elastomer o-rings) could lead to pressurization and rupture of the storage container. Further, the products of these reactions may be corrosive to the storage container itself which could lead to a loss of container integrity. Release of oxide to the ambient environment is of particular concern because process oxides (e.g., those formed by calcination of oxalates) are extremely fine powders with a high propensity for dispersal.

Certain hazards are common to both storage forms. For example, loss of containment due to mechanical breach (as a result of a fall, earthquake, tornado, etc.) is nearly independent of the storage form. However, subsequent dispersion of material is strongly dependent on characteristics such as the particle size distribution. Other hazards include loss of containment and dispersal of material in a fire, the presence of ionizing radiation and the associated exposure of personnel, the remote possibility but serious consequence of a criticality incident, and numerous accident scenarios which result in plutonium dispersal. In each case (except for personnel exposure), the ultimate concern is the potential release of nuclear material into the environment. All of the specifically identified phenomena above are considered hazards because of the potential for plutonium release.

The sections that follow present a semi-quantitative analysis of numerous hazards identified in plutonium storage. An initial overview of fundamental hazards associated with material form is followed by a definition of material at risk (MAR) and a summary of plutonium dispersal hazard from several possible abnormal events.

\section{V.B. Fundamental Hazards Associated with Material Form V.B.1. Chemical Reactivity}

Chemical reactivity is often the preeminent (and only) issue considered in evaluating the suitability of a material for storage. ${ }^{47}$ An assessment of reactivity for a material must consider both thermodynamic and kinetic concerns in the specific storage environment. Plutonium oxide is the most stable form of plutonium in air and other oxygen-rich media. ${ }^{48} \mathrm{Metal}$ and all other plutonium-containing compounds except fluorides $\left(\mathrm{PuF}_{3}, \mathrm{PuF}_{4}\right.$ and $\left.\mathrm{PuF}_{6}\right)$ are unstable relative to oxide in air. Even under stringently inert conditions, the surfaces of all candidate materials are covered by oxide films. Although $\mathrm{PuO}_{2}$ is more stable than other potential storage forms and is considered to be the equilibrium oxide phase in air, recent results for the reaction of water vapor indicate the presence of a thermodynamically-favored, higher valent oxide, a mixed-valent compound with the $\mathrm{Pu}(\mathrm{IV})_{4} \mathrm{Pu}(\mathrm{VI}) \mathrm{O}_{11}$ composition $\left(\mathrm{PuO}_{2.2}\right) .49$

47J.L. Stakebake, J. Nucl. Mat. 38 (1971) 241.

${ }^{48}$ C.A. Colmenares, Prog. Solid State Chem. 9 (1984) 257.

${ }^{49}$ J. L. Stakebake, D.T. Larson, and J.M. Haschke, J. Alloys Comp., manuscript submitted for publication, LA-UR-93-0040 (1993). 
Oxidation reactions of candidate storage forms exhibit a broad spectrum of kinetic behavior. Plutonium metal $>0.5 \mathrm{~mm}$ thick reacts slowly with oxygen and is routinely handled in air without risk of rapid reaction. Spontaneous ignition is only observed if the metal is in a finely divided ( $<0.2 \mathrm{~mm}$ thick) state and if the temperature also exceeds $150^{\circ} \mathrm{C} .{ }^{50}$ In comparison, plutonium hydride is pyrophoric and reacts violently upon exposure to air at room temperature. ${ }^{51}$ Nitride and carbide also spontaneously react with air and moisture. ${ }^{52}$ Chemical reactivities of alloys are difficult to evaluate because information on most alloy oxidation kinetics is unknown. A particularly important reaction of oxide and oxide-coated materials is the rapid and tenacious sorption of water from the atmosphere; ${ }^{53}$ several monolayers of water remain irreversibly bound at $100^{\circ} \mathrm{C}$ in high vacuum. $54,55,56$

Several reactions of plutonium and its compounds are of interest because of their potential safety impact. Loss of containment may occur with oxide powders during a fire or extended storage due to generation of high pressures from adsorbed species. ${ }^{57}$ These and other pressurization processes are discussed in Section V.B.4. Plutonium metal provides a measure of inherent protection from pressurization because of its ability to getter reactive surface species without forming secondary gases such as $\mathrm{H}_{2}, \mathrm{~N}_{2}$ or $\mathrm{C}_{2} \mathrm{H}_{2}$.

\section{V.B.2. Radiolytic Reactivity}

Radioactive decay of plutonium alters the chemical behavior and makeup of molecular and organic compounds in a storage vessel and may alter the stored material or lead to loss of containment. ${ }^{58}$ Radiolytic chemistry is influenced by particle dimension as well as isotopic composition and age of the plutonium. Powdered samples emit a larger fraction of the $5.1 \mathrm{Mev}$ alpha decay particles than do bulk forms. As such, radiolytic reactivity from ${ }^{239} \mathrm{Pu}$ is enhanced in finely divided forms

50J.L. Stakebake, "Plutonium Pyrophoricity," EG\&G Rocky Flats Division Report, Golden, CO, RFP-4517 (June 1992).

51 J.M. Haschke, "Actinide Hydrides," in Topics in f-Element Chemistry: Synthesis of Lanthanide and Actinide Compounds Volume II, Chapter 1, G. Meyer and L.R. Morass eds., Kluwer Academic Publishers, Dordrecht, Netherlands (1991).

52J.M. Cleveland, The Chemistry of Plutonium, American Nuclear Society, La Grange Park, IL (1979).

53J.D. Moseley and R.O. Wing, "Properties of Plutonium Dioxide," Dow Chemical Company Report, Golden, CO, RFP-503 (August 1965).

54J.L. Stakebake and M.R. Dringman, "Hygroscopicity of Plutonium Dioxide," Dow Chemical Company Report, Golden, CO, RFP-1056 (January 1968).

55J.L. Stakebake and L.M. Steward, J. Colloid Interface Sci. 42 (1973) 581.

56J.L. Stakebake, J. Nucl. Mat. 38 (1971) 241.

${ }^{57}$ H.H. Van Tuyl, "Packaging of Plutonium for Storage or Shipment," Internal Report, Pacific Northwest Laboratory, Richland, WA (March 1981).

${ }^{58}$ H.H. Van Tuyl, "Packaging of Plutonium for Storage or Shipment," 1981, ibid. 
compared to bulk samples. Because the high surface area of finely divided plutonium oxide promotes adsorption of large amounts of water, organic molecules, etc., alpha particles from radioactive decay have ample opportunity to interact with adsorbed species in the storage environment. The presence of adsorbates is not limited to fine powders: adsorption is observed for all candidate materials because of ready formation of surface oxide. However, the quantity of adsorbate on massive samples such as alloys or metal is small compared to $\mathrm{PuO}_{2}$ and other finely divided forms. Dioxide products with specific surface areas in excess of $50 \mathrm{~m}^{2} / \mathrm{g}$ are common. 59,60 When exposed to ambient glove box atmosphere for several hours, the mass of a typical oxide sample may increase by more than $1 \%$ due to water adsorption. ${ }^{61}$

Interaction of alpha particles with adsorbed species, organic materials (e.g., plastics), or gases in contact with the nuclear material leads to cleavage of chemical bonds and formation of gaseous products. ${ }^{62,63,64}$ Low-molecular-weight species (e.g. $\mathrm{O}_{2}$ and $\mathrm{N}_{2}$ ) primarily dissociate to form gaseous products (e.g., $\mathrm{NO}_{2}$ ), while heavier molecules tend to polymerize. Radiolysis of water generates hydrogen and oxygen; 65,66 alpha interaction with air produces large percentages of dinitrogen monoxide $\left(\mathrm{N}_{2} \mathrm{O}\right)$ and nitrogen dioxide $\left(\mathrm{NO}_{2}\right) .{ }^{67}$ Products formed by radiolysis of plastics and other organic materials depend on the chemical composition of the source materials and typically include hydrogen. ${ }^{68}$ Radiolytic decomposition of polyvinyl chloride (PVC) apparently forms gaseous hydrogen chloride $(\mathrm{HCl})$.

59J.D. Moseley and R.O. Wing, "Properties of Plutonium Dioxide," 1965, ibid.

60J.L. Stakebake, J. Catalysis 78 (1982) 477.

61J.D. Moseley and R.O. Wing, "Properties of Plutonium Dioxide," 1965, ibid.

62H.H. Van Tuyl, "Packaging of Plutonium for Storage or Shipment," 1981, ibid.

${ }^{63}$ A.R. Kazanjian, P.M. Arnold, W.C. Simmons, and E.L. D'Amico, "Gas Generation Results and Venting Study for Transuranic Waste Drums," Rocky Flats Report RFP-3739, September 23, 1985 (unclassified).

${ }^{64}$ D.K. Roggenthen, T.L. McFeeters, and R.G. Nieweg, "Waste Drum Gas Generation Sampling Program at Rocky Flats," Rocky Flats Report PSD88-037, March 1989 (unclassified).

65J.M. Haschke, et al, "The Reaction of Plutonium with Water: Kinetics and Equilibrium Behavior of Binary and Ternary Phases in the Pu+O+H System," 1983, ibid.

66J.M. Haschke, "Hydrolysis of Plutonium: the Plutonium Oxygen Phase Diagram," in Transuranium Elements: A Half Century, L.R. Moss and J. Fuger eds., American Nuclear Society, Washington D.C. (1992), chapter 40.

${ }^{67}$ D.R. Horrell, R.E. Schlupp, J.M. Haschke, and J.R. Wiley, "A Study of Air in Pits: an Analytical Method (U)," Rockwell International Report, Golden, CO, CD88-2388 (April 1988) (S/RD).

${ }^{68}$ G. Friedlander, J.W. Kennedy, and J.M. Miller, Nuclear Radiochemistry, 2nd ed., John Wiley and Sons, Inc., New York (1966). 
Radiolytic decomposition of molecular and organic species in a storage vessel may have severe consequences. Gaseous radiolysis products will either react with the stored material and/or the storage vessel or will lead to pressurization. The risks associated with low-surface-area samples of metal or alloy are different from those encountered with finely-divided compounds. The low surface area of massive samples limits the quantity of adsorbate in the storage vessel. Further, gettering of hydrogen by plutonium metal reduces risk of container pressurization and container corrosion (though pyrophoric hydride is produced). Plutonium readily reacts with $\mathrm{HCl}$ and $\mathrm{NO}_{2}$ and thus getters these materials as well. Non-metallic powders such as oxide nearly always carry large amounts of adsorbates. These materials typically cannot react with radiolytic gases (e.g., $\mathrm{H}_{2}$ ) or exchange one gas for another.(e.g., reaction of $\mathrm{PuN}$ with $\mathrm{O}_{2}$ yielding $\mathrm{N}_{2}$ ). Mineral acids formed by radiolytic generation of $\mathrm{HCl}$ or $\mathrm{NO}_{2}$ in the presence of moisture may result in container corrosion.

In sum, the magnitude of radiolytic effects is influenced by two important properties of the material to be stored: the specific surface area (and the associated quantity of adsorbates), and the ability of the material to getter radiolytic products. In both cases, plutonium metal and alloys are expected to have considerably fewer problems with radiolytic phenomena than more finely divided $\mathrm{Pu}$ forms.

\section{V.B.3. Helium Release.}

Helium formed by alpha decay of ${ }^{239} \mathrm{Pu}$ and other isotopes provides an additional source for pressure generation during storage. Although the process is slow $\left(\mathrm{t}_{1 / 2}=2.4 \times 10^{4}\right.$ years $)$, the quantity of helium may become significant if the storage period is long and the fraction of helium released by the solid phase is large. The release behavior of massive metal differs from that of oxide because the diffusion rate of helium in metal is relatively slow, and hence, helium is only able to escape from the near-surface region of the solid. By contrast, diffusion of helium in oxide is comparatively rapid and the small particle dimensions allow ready release of all helium created by alpha decay. Experimental data for both ${ }^{238} \mathrm{Pu}$ and ${ }^{239} \mathrm{Pu}$ show that helium is readily released from oxide ${ }^{69,70}$ but is retained as microscopic bubbles at grain boundaries in Pu metal. ${ }^{71}$

Calculations based on the alpha decay rate and helium release kinetics of metal and oxide show that helium pressures slightly greater than one atmosphere are anticipated for oxide in a typical storage configuration after 100 years. ${ }^{72}$ By comparison, the pressure rise expected for storage of an equivalent amount of metal is approximately 0.001 atmosphere. Although the helium release behavior of massive alloys and non-metallic powders is expected to parallel those of the metal and oxide, experimental data are not available.

${ }^{69}$ R.N.R. Mulford and B.A. Mueller, "Measurements of Helium Release from Materials Containing ${ }^{238} \mathrm{PuO}_{2}$," US DOE Report, Los Alamos, NM, LA-5215 (July 1973).

70B.A. Mueller, D.D. Rohr, and R.N.R. Mulford, "Helium Release and Microstructural Changes in ${ }^{238} \mathrm{PuO}_{2}$," US DOE Report, Los Alamos, NM, LA-5524 (April 1974).

${ }^{71}$ M.F. Stevens, T.G. Zocco, and J.H. Steele, "Bubble-Void Formation in Delta Phase Plutonium (U)," US DOE Report, Los Alamos, NM, MST-5-88-9 (August 25, 1988) (S/RD).

72J.C. Martz, "Analysis of Plutonium Storage Pressure Rise," US DOE Report, Los Alamos, NM, NMT-5:92-328 (July 1992). 


\section{V.B.4. Container Pressurization.}

The potential for pressurization of storage containers is a serious concern. As outlined in preceding sections, processes such as chemical reaction, radiolytic decomposition, and alpha decay may produce substantial gas pressure in a container. Concern is greatest for storage of oxide and other finely-divided forms because of their high surface areas and inability to getter gaseous species. Although the rate is likely slow at the storage temperature, chemical reaction of $\mathrm{PuO}_{2}$ with adsorbed water (to form higher-stoichiometry oxides) also produces hydrogen. ${ }^{73}$ For example, an $\mathrm{H}_{2}$ pressure that might be generated in a typical oxide storage configuration ( $3 \mathrm{~kg}$ of $\mathrm{PuO}_{2}$ with a specific surface area of $5 \mathrm{~m}^{2} / \mathrm{g}$ and a single monolayer of adsorbed water in a vessel with 1.5 liter of free volume) is 3.7 atmospheres at $25^{\circ} \mathrm{C}$. Significant, larger pressures of $\mathrm{O}_{2} / \mathrm{H}_{2}$ mixtures are produced if $\mathrm{H}_{2} \mathrm{O}$ radiolysis is the dominant process. As with helium generation, these reactions become increasingly important with time. Another pressure generation process, thermal desorption of water at high temperatures created by a fire or self-heating, is capable of rapidly generating excessively high pressures. ${ }^{74}$ This specific mechanism has caused several notable failures of plutonium storage containers. ${ }^{75}$

Risk of pressurization also exists for storage of plutonium metal and alloys. ${ }^{76}$ Even an extremely small leak in a container can lead to extensive oxidation of stored metal. This process is enhanced by fluctuations in atmospheric pressure. Oxidation of metal or alloys leads to volumetric expansion of the material. The forces associated with this expansion could (and have) ruptured a storage container. A recent failure of a storage container holding a kilogram-size ingot of Pu metal has been attributed to this mechanism. ${ }^{77}$

Appendix $\mathrm{C}$ presents calculations which quantify the degree of pressurization in the storage of qualified and uncharactericized material. These calculations are worst-case estimates which should bound the pressurization which might occur.

\section{V.B.5. Airborne Release of Plutonium.}

Release of plutonium-containing materials to the environment is a serious potential hazard. The two most likely situations that may lead to release are mechanical breach of a storage container and exposure to a fire. These and other scenarios are addressed in more detail in subsequent parts of this section. Once plutonium has been released to the environment, further spread of material is of prime concern. As such, the dispersal risks associated with various forms are directly related to the particle size and form of the material. ${ }^{78}$

73J. L. Stakebake, D.T. Larson, and J.M. Haschke, J. Alloys Comp., manuscript submitted for publication, LA-UR-93-0040 (1993), ibid.

${ }^{74}$ H.H. Van Tuyl, "Packaging of Plutonium for Storage or Shipment," 1981, ibid.

75J.M. Haschke and J.C. Martz, "Metal-Oxide Chemistry and Storage," presentation to the DOE workshop on plutonium storage, LA-CP-93-159, Albuquerque, NM (May 26, 1993).

76J.Lowe, private communication, Atomic Weapons Establishment, Aldermaston, UK (December 17, 1992).

77J.M. Haschke and J.C. Martz, "Metal-Oxide Chemistry and Storage," 1993, ibid.

78J.M. Haschke, "Evaluation of Source-Term Data for Plutonium Aerosolization," US DOE Report, Los Alamos, NM, LA-12315-MS (July 1992). 
The risk associated with mechanical dispersal is different for storage of massive plutonium metal or alloy than for storage of finely-divided compounds. Although some oxide will likely be mechanically dislodged from the surface of massive samples, the fraction of plutonium that might be dispersed is limited to 0.01 mass \% by the thickness of a typical oxide layer. ${ }^{79,80}$ Further extrapolation of rate data below $150{ }^{\circ} \mathrm{C}$ shows that oxidation of the metal after exposure to air at ambient temperature is slow and will not contribute significantly to oxide dispersal even after several days. ${ }^{81}$

In contrast to metal or alloys, relatively large fractions of finely-divided forms are in the dispersible range. ${ }^{82}$ Whereas $20-25$ mass $\%$ of the $\mathrm{PuO}_{2}$ formed by oxidation of the hydride consists of particles with dimensions less than $10 \mu \mathrm{m}, 83100$ mass\% of the oxide formed by pyrolysis of precipitates (e.g., hydrated plutonium oxalate) from aqueous processing is in the potentially dispersible range. 84

Upon release of plutonium metal to the ambient environment, the potential for oxidation and subsequent dispersal by aerosolization exists. The oxidation rate of $\mathrm{Pu}$ in air at $500^{\circ} \mathrm{C}$ and above is modest and constant $\left(0.2 \mathrm{~g} \mathrm{PuO}_{2} / \mathrm{cm}^{2}\right.$ of metal surface $) .85$ The oxide product formed at these temperatures is relatively coarse with less than 0.1 mass\% in the dispersible range. ${ }^{86}$

The possibility of container rupture exists for other powdered forms because of increased gas evolution and pressure and decreased container strength at high temperatures. The pressure is a combined effect arising from chemical reaction, radiolytic decomposition, helium release, thermal desorption, and thermal expansion. Rupture is expected to result in the dispersal of a larger fraction of powdered forms than would be released from massive metal or alloys. On the basis of relative particle size distributions, the quantity of plutonium-containing material released to the environment is 1,000 to 10,000 times greater for process oxide than for massive metal. The possibility of pressurization could also be reduced for powdered materials by certification to verify that significant quantities of adsorbates are not present. ${ }^{87}$

79J.L. Stakebake and L.M. Steward, J. Electro. Soc. 119 (1972) 730.

80J.C. Martz, J.M. Haschke, and J.L. Stakebake, "A Mechanism for Plutonium Pyrophoricity," manuscript submitted to J. Nucl. Mat., LA-UR-93-2655 (1993).

81J.L. Stakebake, J. Less. Common Met. 123 (1986) 185.

82J.L. Stakebake and M.R. Dringman, J. Nucl. Mat. 23 (1967) 349.

83J.M. Haschke, "Evaluation of Source-Term Data for Plutonium Aerosolization," 1992, ibid.

84J.D. Moseley and R.O. Wing, "Properties of Plutonium Dioxide," 1965, ibid.

85J. Mishima, "Plutonium Release Studies II. Release from the Ignited Bulk Metallic Pieces," Batelle Pacific Northwest Laboratory Report, Richland, WA, BNWL-357 (November 1967).

86J. Mishima, "Plutonium Release Studies I. Release from the Ignited Metal," Batelle Pacific Northwest Laboratory Report, Richland, WA, BNWL-205 (December 1965).

${ }^{87}$ H.H. Van Tuyl, "Packaging of Plutonium for Storage or Shipment," 1981, ibid. 
Use of vented containers for powder storage must be evaluated in light of reduced structural integrity of the container, másking of pores by powder intrusion, and the consequences of radiolysis-enhanced corrosion of the nuclear material or the container. Formation of nitrogen oxides from air in a radiolytic environment produces nitric acid if water is also present. ${ }^{88}$ When used in conjunction with a filter, rupture disks which function only on pressurization may alleviate the risk of catastrophic container failure during fires or other accidents while preventing exposure of the nuclear material to external ambient storage environments under normal conditions.

\section{V.B.6. Other Environmental, Safety, and Health Issues.}

Other ES\&H hazards related to storage include nuclear criticality safety, radiation exposure to personnel, and contamination control. Criticality safety procedures are well established for all candidate storage forms. Primary controls include limiting the quantity of stored material and careful inventory and control of physical storage and locations. As an added precaution, storage of plutonium metal and alloys as castings with critically-safe geometries (e.g., thin-walled rings) can reduce the possibility of a criticality incident by deliberate or accidental violation of safety procedures. Criticality safety for finely-divided forms must rely on administrative controls that establish handling procedures and mass limits.

Procedures for limiting worker radiation exposure and controlling spread of radioactive contamination have been well established in the last 40 years. Faust, et al, provide useful guidance on good health physics practices for plutonium operations. ${ }^{89}$ The ingrowth of ${ }^{241} \mathrm{Am}$ in plutonium that contains a few weight percent ${ }^{241} \mathrm{Pu}$ is of particular significance. ${ }^{241} \mathrm{Am}$ emits a large number of $60 \mathrm{Kev}$ photons that can be a significant source of exposure to the hands and forearms in glove box operations. Such plutonium becomes more difficult to handle with time and, at some point, may require remote handling. The corollary of this is that any repackaging should be done while the available equipment can still provide adequate protection, and the need for future handling should be minimized.

Increasingly more stringent requirements for control of occupational exposure and contamination are anticipated (e.g., the DOE RadCon Manual ${ }^{90}$ ) and hence, consideration of advanced material handling technologies which reduce these exposures and risks is worthwhile. The advantage of automation in distancing operators from nuclear material and reducing the likelihood of operator error is widely recognized. 91 Castings of metal or alloy are amenable to automated handling as are powdered materials. Procedures differ for handling finely-divided forms and in some instances are more complex than for transfer of discrete metal components. However, care must be taken in automation to ensure high reliability of robotic components because frequent breakdowns in automated equipment would only transfer radiation exposure from operating to maintenance personnel.

${ }^{88}$ P.G. Stecher, et al, The Merk Index. Seventh Edition, 1960, ibid.

89L.G. Faust, et al, "Health Physics Manual of Good Practices for Plutonium Facilities," Pacific Northwest Laboratory Report, Richland, WA, PNL-6534 (May 1988).

90U.S. Department of Energy Radiological Control Manual, DOE/EH-0256T (June 1992).

${ }^{91}$ J.C. Martz, J.M. Haschke, T.J. Beugelsdjik, and L.E. Bronisz, "Automation and Integration of Site-Return Processing," in Nuclear Materials Technology: Weapons Complex 21 Reconfiguration, US DOE Report, Los Alamos, NM, LALP-92-41 (June 1992) p. 18. 


\section{V.C. Material at Risk}

The fundamental hazards outlined above allow semi-quantitative calculation of the potential for material dispersal. As a basis for these calculations, mass limits are identified for hazardous material in Table 3.

Table 3. Definition of mass limits for material at risk.

\begin{tabular}{|l|c|l|}
\hline Type of Material & MAR Range & \multicolumn{1}{|c|}{ Basis } \\
\hline \hline Metal & $1-10 \mathrm{~kg}$ & $\begin{array}{l}\text { Physical size of components generated or handled. } \\
\text { Typically components with mass }>2 \mathrm{~kg} \text { will be } \\
\text { alloyed material as alloying occurs during } \\
\text { generation from smaller components. }\end{array}$ \\
\hline Oxide & $0.1-3 \mathrm{~kg}$ & $\begin{array}{l}\text { Upper range based on common use of generic } \\
\text { criticality limits for boxes based on metals. Lower } \\
\text { range based on collection of oxide from metals. }\end{array}$ \\
\hline Impure oxide & $1-500 \mathrm{~g}$ & $\begin{array}{l}\text { Range based on plutonium component of } \\
\text { contaminated oxides (i.e. mixed with other } \\
\text { material) being a small weight \% of the total } \\
\text { material. }\end{array}$ \\
\hline
\end{tabular}

\section{V.D. Fires}

Detailed consideration is given to this issue because of the large quantity of bulk plutonium stored throughout the DOE weapons complex. Dispersal of material as a result of container breach during a fire is covered in section V.E. This section focuses on reaction and pressurization of metal and oxide in storage during a fire. Actual fires involved more complicated scenarios and did not involve materials discussed here.

\section{V.D.1. Metals}

Two cases are examined for metals. The first is a theoretical model of a bulk piece of plutonium metal contained in a typical storage can. A generic quantity of plutonium hydride or plutonium metal fines is assumed to use up all available oxygen in the storage can in an instantaneous reaction. The second is a model based on instantaneous reaction of bounding corrosion values estimated at Rocky Flats. It should be emphasized that instantaneous reaction is not physically realistic and is used only as an extremely conservative bound. An alternative description of this assumption is to state that all reactions occur adiabatically.

The basis for this assessment is one kilogram of unalloyed, bulk alpha phase plutonium in a typical food-pack storage can. Heat loadings from corrosion reactions are estimated to demonstrate that maximum obtainable temperatures are below bulk plutonium ignition temperature and that heat losses will effectively prevent ignition of all or portions of the plutonium metal. Details of this calculation, including relevant parameters, are presented in Appendix D.

In sum, the temperature rise attributed to adiabatic reaction is less than $30^{\circ} \mathrm{C}$. As such, this factor does not significantly impact the hazards analysis. Heating as a result of the oxidation reaction does not present a credible risk. This calculation assumed even heat distribution throughout the sample. In an effort to address this limitation, the effect of localized heating on a small portion of the sample has been examined. Details of this calculation are also available in Appendix D. 
All of the temperature increases calculated were well below the ignition temperature for bulk plutonium $\left(\approx 500^{\circ} \mathrm{C}\right)$ as well as typical combustibles found in a processing glove box line. Further, the simple heat loss calculation for a small portion of the metal indicated that minimum heat losses from a small portion of the metal to the bulk of the metal and ambient air amounted to $30 \%$ to $60 \%$ of the total heat available from instantaneous reaction. In experimental studies the flame from a carbon-arc torch was directed onto insulated bulk metal for almost two minutes before self-sustaining ignition occurred. ${ }^{92}$ The simple mathematical examination shown in Appendix D, while not definitive, indicates that the corrosion reactions associated with plutonium metal do not represent a significant plutonium fire hazard in the absence of a large quantity of readily combustible material in proximity of stored material.

\section{V.D.2. Oxides}

The maximum temperature for oxide reactions is not as significant a concern as for metals since the ignition of oxide, a stable material, is not an issue. However, the pressurization of an oxide storage container during a fire is a credible hazard which must be addressed. Thermal desorption of adsorbates during a fire could lead to large pressure increases which might burst a storage container. Decreased material strength at high temperature compounds this problem. Appendix $\mathrm{C}$ presents a calculation of worst-case pressure rises for both qualified and uncharacterized oxide. Note that the values in Appendix $C$ assume room temperature. In the elevated temperature of a fire, these pressures might increase by a factor of two to three as a result of temperature/pressure relationships.

\section{V.E. Material Dispersal}

A simple hazard evaluation of material dispersal, focused primarily on metal corrosion and oxide reactions, has been conducted using a systematic "What-If" technique. A brief summary of the main results is presented in this section. It should be noted that the types of accidents discussed are bounding representations of the spectrum expected to be associated with the corrosion issue. All bounding airborne release fractions (ARFs) and respirable fractions (RFs) are derived from draft DP guidance. 93

\section{V.E.1. Material Dispersal in Fires}

The fire hazard of bulk metal remains controlled by fires external to the metal itself as the corrosion phenomenon is incapable of igniting bulk material. Therefore, no significant safety concern exists in this area. Small plutonium turnings or chips could potentially ignite from the heat generated by corrosion phenomena and such occurrences have been experienced in the history of the DOE complex. The airborne hazard may arise from two situations: self-sustained oxidation and suspension from metal; and suspension from a heated, non-reactive powder $\left(\mathrm{PuO}_{2}\right)$. Airborne release fractions (ARFs) and the Respirable Fraction (RF) of the airborne particles vary for the two situations. However, such material is not typically stored for long periods in vaults unless it has been processed to oxide. Existing safety analyses typically assume up to 1,000 grams of turnings

92R.E. Felt, "Burning and Extinguishing Characteristics of Plutonium Metal Fires," Isochem Inc. Report, Richland, WA, ISO-756 (1967).

${ }^{93}$ Mishima, J., "Recommended Values and Technical Bases for Airborne Release Fractions (ARFs), Airborne Release Rates (ARRs), and Respirable Fractions (RFs) for Materials from Accidents in DOE Fuel Cycle, Ex-Reactor Facilities, Revision 2," DOE-HBK-00913-93 (April 21, 1993). 
with an ARF of $5 \times 10^{-4}$ and a RF of 0.5 , generating a maximum initial airborne source term of 0.25 grams.

Oxides cannot burn as they are already thermally stable, except for minor sub-and super-

stoichiometric reactions. Oxides can be driven airborne by heating if material entrained in the oxide burns or a fire external to the oxide heats the storage can. Using the estimated oxide MAR of 500 3,000 grams and an ARF of $6 \times 10^{-3}$ and a RF of 0.01 yields an initial airborne source term range of 0.03 to 0.18 grams.

\section{V.E.2. Explosions and Pressurization}

There are no explosive phenomena associated with metal storage and corrosion reactions.

However, a significant pressurization reaction is possible if wet oxides are stored. Similar events could also be caused by storage of oxide containing other reactive impurities. The pressurization could conceivably result in energetic venting of the container. The venting energy itself would present no threat as can be demonstrated by a simple TNT-equivalent estimation using the equation for isentropic expansion of an ideal gas. Details of this calculation are shown in Appendix D.4.

Venting of a $150 \mathrm{psi}$ gas is equivalent to less than $0.25 \mathrm{~g}$ of TNT explosion. This value is a credible, upper-limit for storage of a qualified oxide. Unqualified oxide might yield pressures of several thousand psi (see Appendixes C and D.4), equivalent to nearly $15 \mathrm{~g}$ of TNT on venting. However, most containers would likely vent before the maximum pressure could be reached. Radiolytic generation of hydrogen/oxygen mixtures could result in the formation of explosive gas mixtures. The energy equivalent from recombination of these gases could be considerably higher than the mechanical energy released from depressurization.

The main concern with these pressure releases is the potential for plutonium oxide entrainment in the ambient air. Release fractions based on experimental data are likely to overstate the amount of material released as the actual venting does not duplicate the ideal dispersal conditions in the release experiments. For the MAR range from 500 to 3,000 grams, an ARF of 0.05 and a RF of 0.4 yield initial airborne source term in the range of 10 to 60 grams. If process oxide is assumed, and ARF approaching 1.0 is expected, the airborne respirable source term ranges from 200 to 1,200 g. Data presented in Section III suggest that sintering the oxide at $1,000^{\circ} \mathrm{C}$ could reduce the source term to the 50 to $300 \mathrm{~g}$ range.

\section{V.E.3. Spills}

Two major spill scenarios were examined for metal: rupture as a result of a fall, and rupture as a result of metal oxidation and volumetric expansion. In analyzing the fall of a storage container, it is assumed that metal is essentially intact with a surface layer of corrosion products. An estimate of 45 grams oxide per $1 \mathrm{~kg}$ of metal is believed to represent an adequate bound for current conditions and an extremely conservative bound if assumed to represent all metal stored. This estimate yields 45 to 450 grams of oxide over the MAR range of 1 to $10 \mathrm{~kg}$. Assuming that $5 \%$ of this material exists as hydride (an extremely overstated estimate) yields hydride quantity ranging from 2.3 to 23 grams.

Free-fall during transport or handling could rupture a storage container. The impact of metal in a can on an unyielding surface could suspend the powdery corrosion products (i.e., oxide, hydride and metal fines) from the surface of the metal. No consequences are postulated for the metal itself from the impact. If the can maintains its ability to retain particles, no airborne consequences would 
result. Note that unsealed slip-fit cans retained their contents ( $1 \mathrm{lb}$ of ceramic oxide or sand) after free-falls of $4 \mathrm{ft}$ onto an unyielding surface. ${ }^{94}$

If the can looses containment upon impact with the surface, the contents would likely spill onto the floor from the breach. The ARF for $10-\mathrm{ft}$ free-fall spills of powder is not a good representation of the stress imposed on the contents. A very conservative estimate can be obtained by using the ARF/RF for the suspension of a powder from the impact of falling debris, $1 \times 10^{-2} / 0.3$. For the potential MARs above ( 1 to $10 \mathrm{~g}$ of metal with $4.5 \%$ of the mass as oxide, $5 \%$ as hydrides, and $0.5 \%$ as metal fines), the airborne suspension would range from 0.03 to 0.3 grams of plutonium.

Initiation of a truly rapid, pyrophoric reaction of hydride, metal fines, and intermingled oxide would likely result in direct dispersal of the material into the air. The thermal energy from oxidation of the airborne pyrophoric material (hydrides and metal fines) ranges from 1.9 to 19 calories. If the heat generated is assumed to be uniformly radiated in all directions at a distance of $30.4 \mathrm{~cm}(1 \mathrm{ft})$ from the metal, the heat energy impacting the metal surface would range from 0.008 to $0.08 \mathrm{cal}$; insufficient to raise the temperature of the bulk metal to ignition. Considering the suspension of oxide from a surface of metal undergoing a self-sustained oxidation $\left(A R F / R F=5 \times 10^{-4} / 0.5\right)$, the additional source from this scenario would be insignificant.

The second mechanism for a metal release assumes that extended time in a heavily corrosive environment has caused all of the metal to react to oxide. Then the can is either spilled or the volume expansion associated with oxide breaches the can at a seam and all of the oxide is subsequently released from the can. For a MAR range from 1 to $10 \mathrm{kilograms}$ and an ARF of $2 \times 10^{-3}$ and a RF of 0.3 the initial airborne source term range is 0.6 to 6 grams. This number is based on ARF and RF values from spills of approximately 10 feet.

Free-fall spills are also a hazard in storage of oxide. Using the same ARF and RF for the MAR range from 500 to 3,000 grams yields an initial source term range of 0.3 to 1.8 grams. However, the airborne release fraction for process oxide is considerably higher than for oxide derived from oxidation of metal. For example, $100 \%$ of the oxide derived from calcination of oxalate is in the aerosolizable range. As such, the ARF for process oxide may be as high as 1.0: In this case, a source term of 250 to 1,500 grams is found assuming a respirable fraction of 0.5 [the assumption that the small forces involved in a free fall spill of this short distance would deagglomerate half the fine powder involved (generally deagglomeration would involve forces that could be imposed upon the individual particles such as ultrasound) is extremely conservative].

\section{V.E.4. Results}

The bounding initial airborne source terms estimated for the events associated with metal and oxide storage range from 0.01 to 1500 grams. Although 1500 grams is associated with the upper end of the spectrum, all of the values obtained are within the range of typical bounding initial source terms that can be estimated for events at non-reactor nuclear facilities.

The potential dose (Effective Dose Equivalent) to the public from these events was estimated by a simple Gaussian atmospheric dispersion model assuming limiting weather conditions of stability class $F, 1 \mathrm{~m} / \mathrm{s}$ wind speed, and a receptor at $1 \mathrm{~km}$ from the facility. As none of the events specifically discussed in this analysis would be expected to breach facility confinement, it was assumed a standard minimum arrangement of 2 HEPA filters was available to filter the release. Conservatively assuming $99.9 \%$ efficiency for the first and $99.8 \%$ efficiency for the second yields a combined filtration factor of $2 \times 10^{-6}$. Calculated doses are given in the table below.

94Reichmuth, C.R. December 1988. One-Pound Slip-Lid Can Drop Evaluation," SD-CP-TRP027, Internal letter to J.J. Roemer, Westinghouse Hanford Co., Richland, WA. 
The calculated doses are orders of magnitude below the DOE siting guideline of 25 rem. The one potential exception to this would be for severe events that breach building confinement involving complete oxidation of a significant amount of metal or process oxide.

Doses are not calculated for in-facility workers as such calculations are completely assumption driven and difficult to relate to meaningful expectations. However, the assessment indicates that (at least theoretically) a real contamination and inhalation risk exists for workers. This indication is supported by historical experience in the weapons complex where contaminations and associated inhalation doses have occurred. Based on historical experience, however, these events are not anticipated to produce a prompt fatality and the possibility of a large annual committed dose is considered small.

Table 4. Material at risk as a result of certain accident scenarios.

\begin{tabular}{|l|c|c|}
\hline \multicolumn{1}{|c|}{ Event } & MAR Range (grams) & Dose Range (mrem) \\
\hline \hline 1. Metal turning fire & 0.25 & $3 \times 10^{-3}$ \\
\hline 2. Heated oxide & $0.03-0.18$ & $4 \times 10^{-4}-2 \times 10^{-3}$ \\
\hline 3. Pressurized oxide, 5\% ARF & $10-60$ & $0.1-0.6$ \\
\hline 4. Pressurized oxide, 100\% ARF & $200-1,200$ & $2.0-12.0$ \\
\hline 5. Metal shock & $0.01-0.14$ & $1 \times 10^{-4}-2 \times 10^{-3}$ \\
\hline 6. Oxidized metal spill & $0.6-6$ & $7 \times 10^{-3}-7 \times 10^{-2}$ \\
\hline 7. Oxide spill, 4\% ARF & $0.3-1.8$ & $4 \times 10^{-3}-2 \times 10^{-2}$ \\
\hline 8. Oxide spill, 100\% ARF & $250-1,500$ & $3.3-16.7$ \\
\hline 9. Oxide from metal in severe event* & $0.3 / \mathrm{kg}$ & $1,900 / \mathrm{kg}$ \\
\hline
\end{tabular}

*Assumes unfiltered 


\section{Recommendations}

Current plutonium storage practices at Department of Energy facilities can be upgraded to ensure significantly improved levels of safety. The Office of Defense Programs is developing a standard for the anticipated long-term storage of plutonium. This long-term standard will include safety criteria developed as part of the Weapons Complex Reconfiguration (Complex 21) program. As such, material packaged to the long-term standard will be acceptable for storage in the future Complex 21 storage facility. However, new equipment and facilities will be required to fully implement this long-term standard. Phase-in of procedures and processes to meet this long-term standard is expected to take several years at a minimum. As such, a number of short-term actions are suggested to improve the safety of current plutonium storage practices. Numerous references are available for further information associated with these recommendations. $95,96,97,98$, $99,100,101,102$ These recommendations were formulated to allow near-term implementation to provide an increased level of safety until such time as equipment and facilities become available to package plutonium to the upcoming long-term standards. They are applicable to all operations in which plutonium metal or plutonium oxide is stored outside glove-box lines in containment vessels which do not have a certified hermetic seal (e.g., per ANSI N14.5).

- Plutonium metal or plutonium oxides should not be stored in the form of, metal turnings, or particles with specific surface area greater than $1.0 \mathrm{~cm}^{2} / \mathrm{g}$.

${ }^{95}$ ANSI. 1987. American National Standard for Radioactive Materials - Leakage Tests on Packages for Shipment, ANSI N14.5-1987, American National Standards Institute, Inc., New York, NY.

96Bigler, R.M. 1993. "Complex 21 - Plutonium Storage Facility, Material Containment Concepts", presented at the Workshop on Plutonium Storage, May 26-27, 1993, Albuquerque, NM.

97DOE. 1984. ENVIRONMENTAL PROTECTION, SAFETY, AND HEALTH PROTECTION STANDARDS, DOE Order 5480.4, Department of Energy, Washington, DC.

98DOE. 1985. SAFETY REOUIREMENTS FOR THE PACKAGING AND TRANSPORTATION OF HAZARDOUS MATERIALS, HAZARDOUS SUBSTANCE, AND HAZARDOUS WASTE, DOE Order 5480.3, Department of Energy, Washington, DC.

${ }^{99}$ DOE. 1986. SAFETY OF NUCLEAR FACILITIES, DOE Order 5480.5, Department of Energy, Washington, DC.

100L.W. Gray, "Team Summary Report, Complex-21 Plutonium Storage Facility, Materials Identification and Acceptance Criteria (MIAC) Team", presented at the Workshop on Plutonium Storage, May 26-27, 1993, Albuquerque, NM.

101IAEA, REGULATIONS FOR THE SAFE TRANSPORT OF RADIOACTIVE MATERIALS, Safety Series No. 6, 1985 Edition (As AMENDED 1990), International Atomic Energy Agency, Vienna, Austria.

102W. T. Wood, "An Overview of the Complex-21 Plutonium Storage Facility", presented at the Workshop on Plutonium Storage, May 26-27, 1993, Albuquerque, NM. 
- Direct handling of material should be minimized (can result in exposure of 30 to $100 \mathrm{mrem} / \mathrm{handling}$ operation).

- Adequate inspection of containers for abnormalities (e.g. mass change, deformation, discoloration) should occur through means such as visual inspection, weighing, or even video surveillance where such capability exists. These data should be recorded for safety and Material Control and Accountability (MC\&A) evaluations. The Task Force considers reasonable visual inspection requirements to be one week and one month after initial containment of material from processes, and yearly thereafter.

- All packages containing more than $0.5 \mathrm{~kg}$ of plutonium metal should be placed on an annual surveillance schedule in which the total mass of the package is determined to an accuracy of $\pm 0.5 \mathrm{~g}$ and compared with the mass determined in the preceding year, and if possible, with the initial (reference) mass determined at the time of packaging. A storage package should be evaluated (e.g., opened and inspected, radiographed, etc.) if any of the following conditions are met:

a. The outer storage vessel is bulged or distorted.

b. Hydride-catalyzed oxidation is suspected. Such reaction is indicated by a mass increase in either of two circumstances.

i) For packages whose mass continues to increase since initial packaging or for which historical mass data is unavailable, a mass increase greater than $15 \mathrm{~g}$ per kilogram of plutonium over a one-year period indicates a hydride-catalyzed oxidation reaction ${ }^{103}$. Continuing mass increase is indicative of a leaking container.

ii) For packages whose mass has remained constant over a period of several years (less than $\pm 0.5 \mathrm{~g}$ change) at the reference value, an annual mass increase of more than $2 \mathrm{~g}$ per kilogram of plutonium is evidence of hydride-catalyzed reaction. Such packages are particularly suspect since they indicate that a previously sealed container may now be breached and that the reaction could lead to rapid failure within 12 to 24 months.

c) If the measured package mass relative to the reference mass corresponds to formation of oxide with a volume exceeding $10 \%$ of the free volume of the inner vessel. (Each one-gram increase in mass corresponds to formation of $1.5 \mathrm{~cm}^{3}$ of oxide with a density at $50 \%$ of the theoretical value.)

- Inspection practices at sites should be codified in surveillance plans. These plans should reflect facility operating status. Personnel protection practices should include radiological surveillance during all handling operations, anti-contamination clothing, gloves and, if necessary, respiratory protection.

${ }^{103} \mathrm{~A}$ higher oxidation rate may occur if the metal is in a high surface area configuration such as sheet of foil. The maximum annual increase for normal (uncatalyzed) oxidation of a given metal geometry can be calculated using a reaction rate of $3 \times 10^{-7} \mathrm{~g}$ oxygen $/ \mathrm{cm}^{2}$-minute measured for alpha-phase plutonium under moist conditions at $50^{\circ} \mathrm{C}$.) 
- Inspection of containers should be integrated with inspections for MC\&A to minimize container handling and attendant radiation exposure to levels as low as reasonably achievable.

- Containers identified in inspection as possessing abnormalities should be repackaged in accordance with well-defined procedures. When handling these containers outside of glove box or conveyor confinement, the potential for airborne contamination and personnel inhalation must be explicitly evaluated with respiratory protection requirements specified accordingly.

- Examination and repackaging should be carried out in a glove box, preferably inert ( $<100 \mathrm{ppm} \mathrm{O}_{2}$ if possible), and in accordance with well-developed procedures to minimize worker risk. Due to the potential for pyrophoricity of plutonium metal fines, accumulations of combustible material, such as rags, should not be permitted in repackaging areas. Even bulk metals should be treated as potentially having surface metal fines due to corrosion.

- As an interim measure, material that is repackaged may be placed in food pack cans or slip-fit (Vollrath) containers with secured lids. If at all possible, metal should be repackaged in a configuration containing at least one gas-tight seal. No plastic should be in direct contact with plutonium metal or oxide, and use of plastic in outer layers of packaging should be minimized. QA measures, labeling, and material characterization are essential. It is important that the material and storage packaging specifics be thoroughly documented to avoid future uncertainties requiring additional handling solely for characterization.

- When packaging metal, hazardous or pyrophoric material, such as plutonium hydride, should be removed. It is not, however, necessary to remove protective oxide film. Metal should be packaged in as dry and inert an environment as possible to minimize corrosion ( $<100$ ppm $\mathrm{H}_{2} \mathrm{O}$ ).

- It is strongly advised that impure oxides from sources other than metal be thermally stabilized at $1000^{\circ} \mathrm{C} \pm 100^{\circ} \mathrm{C}$ for 1 hour. This process serves to remove excess moisture, ensure complete conversion of substoichiometric material, and aids smallparticle coalescence which partially mitigates the dispersal risk. If a capability for hightemperature firing does not exist, oxides can be stored inside Zone 1 confinement systems without stabilization provided slip-fit containers are used to preclude pressure build-up. Oxides outside of Zone 1 confinement should be stored in food pack or other sealed cans and, therefore, should be stabilized if at all possible.

- Due to its greater potential for dispersion in severe accidents, oxide should have priority over metal for storage in structurally robust vaults. To insure significant corrosion of oxide has not occurred in stored metal, the material should be characterized. Due to the buildup of impurities such as Am-241, the characterization should be performed in the immediate future and should make full use of small sample statistical methods. This study should be integrated with a site's surveillance plan as well. 


\section{Bibliography}

\section{General Plutonium Technology:}

J.M. Cleveland, The Chemistry of Plutonium, American Nuclear Society, La Grange Park, IL (1979).

O.J. Wick, ed., Plutonium Handbook, A Guide to the Technology - Volumes I and II, American Nuclear Society, La Grange Park, IL (1980).

C.M. Unruh, "The Radiological Physics of Plutonium," in Proceedings - Plutonium as a Reactor Fuel, F.G. Dawson, ed., General Electric Hanford Atomic Products Operation, Richland, WA, HW-75007 (December 1962).

\section{Plutonium Storage:}

J.L. Stakebake, "The Storage Behavior of Plutonium Metal, Alloys, and Oxide: A Review," J. Nucl. Mat. 38 (1971) p. 241.

L.E. Musgrave, "Storage of Unalloyed Plutonium in Metal Cans," Rocky Flats Report PRD950461-105, July 25, 1973 (unclassified).

H.H. Van Tuyl, "Packaging of Plutonium for Storage or Shipment," Internal Report, Pacific Northwest Laboratory, Richland, WA (March 1981).

J.C. Martz and J.M. Haschke, "Long-Term Storage of Plutonium: An Overview (U)," Los Alamos Report LA-CP 92-275, October 1992 (UCNI).

J.M. Haschke and J.C. Martz, "Storage of Plutonium Extracted from Weapons (U)," US DOE Report, Los Alamos, NM, LA-12551-MS (March 1993) (S/RD).

J.M. Haschke and J.C. Martz, "Interim Storage of Excess Plutonium: An Assessment of Options (U)," US DOE Report, Los Alamos, NM, LA-12624-MS (July 1993) (S/RD). 


\section{Appendix A. Attendance List and Agenda for Plutonium Storage Workshop.}

ALBUQUERQUE, N.M.
May 26-27, 1993

\begin{tabular}{|c|c|c|c|}
\hline NAME & AFFILIATION & TELEPHONE & FAX \\
\hline David Michlewicz & DOE/DP-62 & (301) 903-5519 & 3-7065 \\
\hline Dae Chung & DOE/DP-62 & (301) 903-3968 & -7065 \\
\hline Valerie Maness & LLNL & (510) 423-3208 & (510)424-6889 \\
\hline Brian R. Fitzpatrick & WHC & (509) 373-4119 & \\
\hline Lisa Chan & PP-42 & (202) 586-9637 & -1217 \\
\hline William C. White & DOE/DP-273 & (301) 903-5522 & -5821 \\
\hline Leonard W. Gray & LLNL & (510) $422-1554$ & (510) 422-3165 \\
\hline Daniel E. Glenn & DOE/LAAO & $(505) 665-6351$ & (505) 667-4872 \\
\hline Kurt T. Juroff & DOE/DP-6.1 & (301) 903-2636 & (301) 903-3186 \\
\hline Rowland Felt & WINCO & (208) 526-3409 & (208) 526-0665 \\
\hline August J. Stapf & WSRC & (803) 952-4798 & (803) 952-4747 \\
\hline Jeffrey B. Schaadt & WSRC & (803) 952-4758 & (803) 952-4429 \\
\hline H. Allen Gunter & DOE/SR & (803) 725-8834 & (803) 725-5017 \\
\hline John E. Myers & DOE/SF & (510) 422-3357 & (510) 423-5650 \\
\hline Corey A. Cruz & DOE/AL & (505) 845-4282 & (505) 845-4722 \\
\hline John M. Haschke & LANL & (505) 665-3342 & (505) 665-8002 \\
\hline Thomas Wright & DOE/HQ/DP-6.2 & (301) 903-3661 & (301) 903-9471 \\
\hline Paul Hartman & DOE/ONS-Rky Ft & (303) 966-5379 & (303) 966-7890 \\
\hline Thomas J. O'Connor & DOE/ONS-NS-10 & (301) 903-6781 & (301) 903-7358 \\
\hline Bob Reece & DOE/RF & (303) 966-6728 & 5857 \\
\hline Harry F. Lutz & LLNL & (510) 423-2968 & (510) 424-6889 \\
\hline Michael F. Stevens & LANL/NMT-5 & (505) 667-4414 & $(505) 665-8002$ \\
\hline Jofu Mishima & SAIC & (509) 943-3133 & (509) 943-5121 \\
\hline
\end{tabular}




\begin{tabular}{|l|l|l|l|}
\hline Joe Woods & DP-682 & $(301) 903-5354$ & $(301) 903-8047$ \\
\hline William Miller & DP-65 & $(301) 903-9841$ & $(301) 903-6628$ \\
\hline Francisco C. Cheng & DP-643 & $(301) 903-7097$ & \\
\hline David Nickless & DOE/RFO & $(303) 966-5221$ & $(303) 966-5857$ \\
\hline Alan K. Williams & SAIC & $(301) 358-8228$ & $(301) 428-0145$ \\
\hline Randy M. Bigler & WSRS & $(803) 952-4542$ & $(803) 952-4205$ \\
\hline Beth Conrad & CAI & $(303) 966-3007$ & $(303) 966-4673$ \\
\hline Gregg Nishimoto & RFO & $(303) 966-7022$ & $(303) 966-5887$ \\
\hline John C. Breteke & SUEC/AL & $(505) 845-4610$ & $(505) 845-4609$ \\
\hline Raymond P. Wagner & LANL & $(505) 667-0645$ & $(505) 665-6160$ \\
\hline Brent H. Ives & LLNL & $(510) 423-2636$ & $(510) 423-1685$ \\
\hline Mel Taie & LLNL & $(510) 423-1679$ & $(510) 423-2204$ \\
\hline Liz Roybal & DOE/AL/SPD & $(505) 845-5684$ & $(505) 845-6431$ \\
\hline Paul Groves & HQ DOE/DP20.1 & $(301) 903-8237$ & $(301) 903-5604$ \\
\hline Steve Goodrum & DOE/AL & $(505) 845-5282$ & $(505) 845-4837$ \\
\hline Dan Rose & DOE/AL/WMOSD & $(505) 845-5179$ & $(505) 845-4664$ \\
\hline Lou Rodgers & Westinghouse & $(509) 373-2185$ & $(509) 373-2150$ \\
\hline Earl Whiteman & DOE/AL & $(505) 845-6280$ & \\
\hline John Hargreaves & EG\&G-Rky Flts & $(303) 966-2889$ & $(303) 966-4063$ \\
\hline John R. Winkel & EG\&G-RFP & $(303) 966-2636$ & $(303) 966-6022$ \\
\hline James E. Selle & EG\&G RFP & $(303) 966-4227$ & $(303) 966-2982$ \\
\hline Warren Wood & LANL & $(505) 665-8996$ & $(505) 665-8991$ \\
\hline Don Brunell & DOE-NS & $(505) 667-3527$ & $(505) 665-7709$ \\
\hline David N. Olsen & Argonne & $(208) 533-7459$ & $(208) 533-7151$ \\
\hline Gail Jackson & Argonne & $(208) 533-7044$ & $(208) 533-7577$ \\
\hline John Krsul & Argonne & $(208) 533-7318$ & $(208) 533-7577$ \\
\hline
\end{tabular}




\section{DAY 1}

\section{8:00}

Opening Remarks

D. Chung, DOE/DP-626

- Workshop Background

- Workshop Objectives//Desired Outcome

8:30 Review of Plutonium Metal and Oxide Properties Relevant to Storage
A. Williams, SAIC Moderator
J. Mishima, SAIC
R. Felt, WINCO
J. Haschke, LANL

- General Metal and Oxide Corrosion

- Pu Fires/Metal Interactions/Oxide

Experience

- Metal/Oxide Chemistry and Storage

$10: 30$

BREAK

Presentations on Pu/Oxide Storage at DOE Sites

Rocky Flats

D. Nickless, DOE/RFO

12:15

LUNCH

$1: 15$

LANL

Savannah River

M. Stevens, LANL

J. Stapf, WSRC

3:15 BREAK

$3: 30$

Hanford

LLNL

Argonne

1969 Rocky Flats Fire

L. Rodgers, WHC

M. Taie, LLNL

J. Krsul, ANL-W

R. Felt, WINCO

\section{$\underline{\text { DAY } 2}$}

9:00 Presentation of Advanced Storage Concepts

Interim Storage

Complex-21 Pu Storage Facility

W. White, DOE/DP-273

Overview

Materials Identification and

Acceptance Criteria

Containment Concepts

L. Chan, DOE/DP-42

W. Wood, LANL

L. Gray, LLNL

R. Bigler, WSRC 
10:30 BREAK

Development of "Strawman" Criteria

10:45 Metal and Oxide Working Group Breakout (consider impact on/of ALARA, criticality, and safeguards and security)

- Containers

- Inspections

- Modeling

- Material Qualification

- Atmosphere Qualification

12:00 LUNCH

1:00 Working Group Reports

3:00 BREAK

3:15 Discussion (approach toward consensus)

5:00 Assignment of Action Items

5:30 Adjourn Workshop 


\section{Appendix B. Pelletizing of Plutonium Oxide.}

Conditions and equipment required for pelletizing plutonium oxide are:

- Powder receipt, measurement, and handling capability,

- Vacuum degassing equipment (if the oxide cannot be certified to be free of moisture),

- Powder milling and grinding equipment to attain small particle sizes required for successful sintering,

- Furnaces for temperature in the range of $1700^{\circ} \mathrm{C}$,

- Presses capable of loads on the order of 60,000 psi to compress the powder,

- Molds and dies for forming the pellets at temperature in the range of $1700^{\circ} \mathrm{C}$,

- Pellet inspection, handling and packaging capability; packaging should be in hermetically sealed containers in an inert or dry air atmosphere,

- Glove box atmosphere should be inert or dry air, and

- Glove boxes should be shielded to reduce dose from ${ }^{241} \mathrm{Am}$ ingrowth, but totally remote operation may not be necessary.

Concerns include:

- The technology was developed for space heating/power generation. How much effort is required to apply the technology to stabilization of oxide powder?

- Developmental efforts are necessary to determine the correct level of pellet porosity (as measured by density) to ensure release of helium formed by alpha decay.

- Additional processing increases the cost, complexity, and radiation exposure of the process operators.

- Product is still susceptible to fragmentation by crush-impact forces. 
The existing capability to convert plutonium oxide to sintered pellets at DOE facilities is as follows: Rocky Flats

- All required equipment except for powder presses, sintering furnaces and molds and dies,

- Compression presses which could be used to press pellets.

\section{HANFORD - Fuel Materials Examination Facility}

- Existing fuel fabrication facility for the Fast Flux Test Facility - never been operated,

- Facility meets most of DOE Order 6430.1A requirements except for Class 1E power supplies,

- Vault with 3-4 MT oxide storage capacity,

- Large sintering furnaces, pellet presses and dies for small (approx. $5 / 8$ inch diameter by $1 / 2$ inch long) pellets,

- Production capacity of $6 \mathrm{MT} / \mathrm{yr}$; could be more than $10 \mathrm{MT} / \mathrm{yr}$ if larger pellets are manufactured,

- FMEF rough costs: $\$ 30-40 \mathrm{M}$ and 2 years to prepare, and $\$ 15-20 \mathrm{M}$ per year to operate.

\section{$\underline{\text { LANL }}$}

- Capability for gram quantities only (Pu-238) and facilities are in use to meet Cassini mission requirements,

- Previous oxide fuel R\&D equipment no longer available.

\section{Savannah River - Puff Facility}

- Furnace capable of temperature up to $1,600^{\circ} \mathrm{C}$,

- Press to make 1 inch diameter by 1 inch long pellets and inerted glove boxes, but only in batch sizes of a fraction of a kilogram,

- Facility in very poor condition; feasibility, cost and schedule to refurbish it are uncertain. 


\section{Appendix C. Calculation of Worst-Case Pressure Rise for Stored Plutonium Oxide.}

The four most likely pressurization mechanisms in the storage of nuclear material are helium release due to alpha decay, chemical reaction of material within the storage container, radiolytic reaction of components within the storage container, and thermal desorption of species from the stored nuclear material. The rate of pressurization (per $\mathrm{kg}$ of plutonium) for each of these terms is dependent on the particle size and surface area of the stored material. Further, the latter three terms are strongly dependent on the quantity of foreign material introduced into the storage container. High-surface-area media (such as $\mathrm{PuO}_{2}$ ) have the capacity to introduce large amounts of other compounds into the storage environment. As such, the potential for pressurization is considerably larger in the storage of oxide than in the storage of metal. We briefly outline the degree of water absorption on $\mathrm{PuO}_{2}$ before discussing each of these mechanisms.

Plutonium dioxide can absorb in excess of $25 \mathrm{mg} \mathrm{H}_{2} \mathrm{O} / \mathrm{g} \mathrm{PuO}_{2}$. Some of this moisture is released by heating to various temperatures. The material which is removed by heating from room temperature to $50^{\circ} \mathrm{C}$ is termed "physisorbed". Stakebake and Steward ${ }^{C 1}$ have shown the physisorbed portion to be near $18 \mathrm{mg} \mathrm{H}_{2} \mathrm{O} / \mathrm{g} \mathrm{PuO}_{2}$. Further heating results in continued desorption of water as shown in figure 1 (see Section II). On heating to $1,000{ }^{\circ} \mathrm{C}$ an additional $10 \mathrm{mg} \mathrm{H} 20 / \mathrm{guO}_{2}$ is removed. This water is termed "chemisorbed".

However, the concern in storage of $\mathrm{PuO}_{2}$ is not with what was removed prior to storage, but with what remains and is introduced into the storage vessel. Several researchers have reported that water is irreversibly bound on the $\mathrm{PuO}_{2}$ surface and that desorption experiments only measure removal of water which was absorbed during the previous single exposure to $\mathrm{H}_{2} \mathrm{O}$. Water remaining from exposures prior to the last is not removed on heating. Such data give some concern in the storage of uncharacterized material in which the process history is unknown and the quantity of adsorbed species cannot be determined.

As is seen below, the pressurization which could result from uncharacterized material is large. Conversely, the pressurization from characterized and controlled material is small. For the purposes of calculation, we assume that $30 \mathrm{mg} \mathrm{H}_{2} 0 / \mathrm{g} \mathrm{PuO}_{2}$ is introduced in the worst case for uncharacterized oxide, while suitably prepared and characterized $\mathrm{PuO}_{2}$ contains less than $1 \mathrm{mg} \mathrm{H} \mathrm{H}_{2} \mathrm{O} / \mathrm{g} \mathrm{PuO}_{2}$.

\section{C.1. Helium release}

In metal storage, little if any pressure rise is anticipated because helium is retained in the metal and does not reach the gas phase. For oxide, a pressure increase of $1.055 \times 10^{-4} \mathrm{~mol}$ helium $/ \mathrm{kg} \mathrm{PuO}_{2}$ per year is expected since all helium escapes. Assuming $4.5 \mathrm{~kg}$ of $\mathrm{PuO}_{2}$ in a storage can with a total volume of $1,850 \mathrm{~cm}^{3}$ yields a pressure rise of 5.54 torr/yr, or a total pressure rise of 277 torr (5.35 psia) after 50 years. This is the only certain source of pressure rise since alpha-decay of ${ }^{239} \mathrm{Pu}$ is assured.

C1J.L. Stakebake and L.M. Steward, J. Colloid Interface Sci. 42 (1973) 581. 


\section{C.2. Chemical reaction}

It is difficult to predict the pressure increase arising from chemical reaction. A calculation must assume a quantity of adsorbate which reacts with the stored nuclear material. Further, the kinetics of the reaction will determine the rate of pressure increase. Certain materials and reactions are well characterized (such as the reaction of $\mathrm{H}_{2} \mathrm{O}$ with Pu metal), while others are suspected but the rates unknown (such as the reaction of $\mathrm{H}_{2} \mathrm{O}$ with $\mathrm{PuO}_{2}, 5 \mathrm{PuO}_{2}+\mathrm{H}_{2} \mathrm{O}$ $\rightarrow \mathrm{Pu}_{5} \mathrm{O}_{11}+\mathrm{H}_{2}$ ). In the worst case, it is assumed that all species react and give gaseous products. For uncharacterized material containing $30 \mathrm{mg} \mathrm{H}_{2} \mathrm{O} / \mathrm{g} \mathrm{PuO}$, complete reaction with $\mathrm{PuO}_{2}$ would yield $1.67 \mathrm{~mole}_{2} / \mathrm{kg} \mathrm{PuO}_{2}$ or, in the specified storage container (4.5 $\mathrm{kg} \mathrm{PuO}_{2}, 1,850 \mathrm{~cm}^{3}$ total volume), a total pressure of $115.3 \mathrm{~atm}$ (1,695 psia). The chance that such complete reaction would occur during storage is unknown but expected to be very small. More likely is partial reaction giving a much lower hydrogen pressure. Indeed, the buildup in hydrogen pressure seen in past storage of plutonium oxide may be due in part to this mechanism (as opposed to radiolytic decay of water or organic materials as sometimes suggested). A more credible pressure rise expected for well-characterized material $\left(1 \mathrm{mg} \mathrm{H}_{2} \mathrm{O} / \mathrm{g} \mathrm{PuO}_{2}\right)$ is $0.056 \mathrm{~mole}_{2} / \mathrm{kg} \mathrm{PuO}_{2}$. In the given configuration, this yields a total pressure rise of $3.84 \mathrm{~atm}(56.5 \mathrm{psia})$. This latter number also assumes complete reaction of moisture with $\mathrm{PuO}_{2}$, something which is difficult to predict but probably not likely.

Note that if complete chemical reaction of moisture occurs, there is no remaining adsorbate for either radiolytic reaction or thermal desorption.

\section{C.3. Radiolytic reaction}

Radiolytic decomposition of water and other organic materials is also difficult to predict. In the worst case, one can assume that all species are radiolytically decomposed. As such, the worst-case for radiolytic decomposition is 1.5 times that for chemical reaction (each $\mathrm{H}_{2} \mathrm{O}$ radiolyzes to $1 \mathrm{H}_{2}$ and $1 / 2 \mathrm{O}_{2}$ ) (2,543 psia for uncharacterized material, $84.8 \mathrm{psia}$ for certified).

An alternative approach involves calculating the rate of radiolytic decay. This calculation is more involved and requires a specification of surface-area of the material and the G-value for hydrogen production from organic and water decay. One can assume an infinite sink of radiolizable material to predict a worst-case pressurization (a near-infinite sink might be the presence of plastic bagging, for example). Using a surface area of $50 \mathrm{~m}^{2} / \mathrm{g} \mathrm{PuO}_{2}$, an $\alpha$ escape depth of $0.2 \mu \mathrm{m}$, and a G-value of $2.0 \mathrm{H}_{2} / 100 \mathrm{eV} \alpha$ particle emission, a hydrogen generation rate in excess of $2,400 \mathrm{~mol} \mathrm{H}_{2} /$ year is found. Obviously, this number is excessive (since it assumes that radiolizable material is in intimate contact with $\mathrm{Pu}$ throughout the $50 \mathrm{~m}^{2} / \mathrm{g}$ surface area). Hence, is must be assumed that all radiolizable material can react and the numbers stated in the paragraph above are the worst-case pressurizations. 


\section{C.4. Thermal desorption}

If material is characterized and processed to remove physisorbed components, little if any pressurization is expected upon heating. Conversely, uncharacterized material could release as much as $20 \mathrm{mg} \mathrm{H}_{2} \mathrm{O} / \mathrm{g} \mathrm{PuO}_{2}$ on heating (see figure 1). This corresponds to a water release of $1.11 \mathrm{~mol} \mathrm{H}_{2} \mathrm{O} / \mathrm{kg} \mathrm{PuO}_{2}$ or a pressure rise of $76.9 \mathrm{~atm}(1,130 \mathrm{psia})$ in the specified storage container. Note that several previous container ruptures have been attributed to this mechanism, including the 1979 incident at Hanford which prompted the Van Tuyl investigation. The above calculation is extremely simplistic and does not account for equilibrium conditions and condensation on other surfaces. These issues are extremely complex and beyond the scope of this analysis.

\section{C.5. Summary}

Under worst case conditions, the total pressure rise involves total release of helium and complete reaction of adsorbates on the $\mathrm{PuO}_{2}$ surface. For uncharacterized material, a pressure rise of 1700 to $2550 \mathrm{psia}$ is calculated after 50 years of storage. This term is dominated by the 1695 to 2543 psia pressure rise due to reaction, decomposition, and desorption of the $30 \mathrm{mg} \mathrm{H}_{2} \mathrm{O} / \mathrm{g} \mathrm{PuO}_{2}$ present in the initial material. The released gas is composed of either water or hydrogen, depending on which mechanism pressurized the container. Though these are worst-case estimates, the likelihood of a pressurization of this magnitude is considered small.

Well characterized material ( $1 \mathrm{mg} \mathrm{H} \mathrm{H}_{2} \mathrm{O} / \mathrm{g} \mathrm{PuO}_{2}$ ) is expected to have a much lower pressurization. Under the worst case, a total pressure rise of 61.8 to 89.8 psia is calculated after 50 years. This term is also dominated by the 56.5 to 84.5 psia rise from reaction, decomposition, and desorption. Again, the likelihood of a pressurization of this magnitude is difficult to predict but the likelihood is considered extremely small. This statement is supported by the years of successful storage experience with well-characterized oxide. 


\section{Appendix D. Summary of Calculations for Heat Generation, Temperature Rise, and Plutonium Dispersion.}

\section{D.1. Initial Calculational Assumptions}

D.1.a. Plutonium Properties from $^{\mathrm{D} 1, \mathrm{D} 2}$

Density

Specific Heat

Heat of Oxidation

$\mathrm{PuO}_{1.98}$

$\mathrm{PuH}_{2}$

$\mathrm{Pu}$

Bulk Ignition Temp.
- $19.86 \mathrm{~g} / \mathrm{cm}^{3}$

- $3.6 \times 10^{-2} \mathrm{cal} / \mathrm{g} \mathrm{K}$

- 4,500 cal/mole

- 273,200 cal/mole

- $252,800 \mathrm{cal} / \mathrm{mole}$

- Slightly above $500^{\circ} \mathrm{C}$

D.1.b. Can Properties

from $^{\mathrm{D} 3, \mathrm{D} 4}$

$\begin{array}{ll}\text { Diameter } & -10.3 \mathrm{~cm} \\ \text { Height } & -11.9 \mathrm{~cm} \\ \text { Thickness } & -10 \mathrm{mil}=0.025 \mathrm{~cm} \\ \text { Density } & -8 \mathrm{~g} / \mathrm{cm}^{3} \\ \text { Specific Heat } & -0.12 \mathrm{cal} / \text { mole K }\end{array}$

D.1.c. Bounding Corrosion Estimates for Rocky Flats Unalloyed Metal Storage
QuantityDS
Composition
- $45 \mathrm{~g}$ oxide/kg of metal
- $5 \% \mathrm{PuH}_{2}, 0.5 \% \mathrm{Pu}$ metal fines

It is recognized that the above estimates cannot be called definitive. It is the judgment of the experts in the DP task force that these estimates are highly conservative.

D1O.J. Wick, ed., Plutonium Handbook. A Guide to the Technology - Volumes I and II, American Nuclear Society, La Grange Park, IL (1980).

D2 J.L. Stakebake, "Plutonium Pyrophoricity," EG\&G Rocky Flats Division Report, Golden, CO, RFP-4517 (June 1992).

D3H.H. Van Tuyl, "Packaging of Plutonium for Storage or Shipment," Internal Report, Pacific Northwest Laboratory, Richland, WA (March 1981).

D4R.H. Perry, ed., Handbook of Chemical Engineering, 5th Edition, McGraw-Hill, New York (1973).

D5Stakebake, J.L., J.E. Selle and J.R. Winkel. October 29, 1990. Technical Evaluation for the Safe Handling of Oxidation Products produced During Plutonium Storage, (undocumented). 


\section{D.2. Temperature Rise Sample Calculation}

1. Volume of Plutonium

$1,000 \mathrm{~g} / 19.86 \mathrm{~g} / \mathrm{cm}^{3} \approx 50 \mathrm{~cm}^{3}$

2. Volume of Can

$\pi(5.15 \mathrm{~cm})^{2} * 11.9 \mathrm{~cm} \approx 1,000 \mathrm{~cm}^{3}$

3. Air in Can

$$
1,000 \mathrm{~cm}^{3}-50 \mathrm{~cm}^{3}=950 \mathrm{~cm}^{3}
$$

4. Oxygen Available in the Can

Assume the can is filled with air at $25^{\circ} \mathrm{C}, 1$ atmosphere pressure, and $100 \%$ relative humidity.

a. Oxygen in Air

i. liters $/$ mole of air at $25^{\circ} \mathrm{C}=22.4 \mathrm{I}(298 \mathrm{~K} / 273 \mathrm{~K})=24.5$ liters

ii. air in can $=0.95 \mathrm{y} / 24.5 \mathrm{l} / \mathrm{mole} \approx 0.04$ moles

iii. oxygen available $=0.04$ moles $* 0.21 \approx 8 \times 10^{-3}$ moles $\mathrm{O}_{2}$

b. Oxygen from Water Vapor

i. Saturation water pressure at $25^{\circ} \mathrm{C}=3.2 \mathrm{kPa}$

ii. Mole \% water vapor in air at $1 \mathrm{~atm}=100 * 3.2 \mathrm{kPa} / 101.3 \mathrm{kPa}=3.2 \%$

iii. Water vapor in can $=0.04$ moles air $* 0.032 \approx 1.0 \times 10^{-3}$ moles

iv. Assume all water vapor disassociates due to radiolysis

$2 \mathrm{H}_{2} \mathrm{O}->2 \mathrm{H}_{2}+\mathrm{O}_{2}$

$\mathrm{O}_{2}$ available $=1.0 \times 10^{-3} * 0.5=5 \times 10^{-4}$ moles

c. Total oxygen $=8 \times 10^{-3}+5 \times 10^{-4}=8.5 \times 10^{-3}$ moles

5. Heat generated

Assume: (1) instantaneous reaction, and (2) all oxidizing material is plutonium hydride.

The stoichiometric reaction of concern is

$$
2 \mathrm{PuH}_{2}+3 \mathrm{O}_{2}-->\mathrm{PuO}_{2}+2 \mathrm{H}_{2} \mathrm{O}
$$

a. Maximum hydride that can react $=8.5 \times 10^{-3}$ moles $\mathrm{O}_{2} * 2 / 3=5.7 \times 10^{-3}$ moles

b. Heat liberated $=5.7 \times 10^{-3}$ moles $* 273,200 \mathrm{cal} / \mathrm{mole} \approx 1560 \mathrm{cal}$ 


\section{Temperature rise}

Assume: (1) heat is equally absorbed by an insulated system consisting of the can and the plutonium since the reaction is instantaneous, and (2) the heat absorbed by the air in the can is ignored.

a. Mass of the can

i. Volume of structural metal in can $=$ Volume of cylindrical portion + volume of ends + volume of crimp seals

(1) Cylindrical can volume $=\left[\pi(5.15 \mathrm{~cm})^{2} * 11.9 \mathrm{~cm}\right]-[\pi(5.15 \mathrm{~cm}-$ $\left.0.025 \mathrm{~cm})^{2} * 11.9 \mathrm{~cm}\right] \approx 10 \mathrm{~cm}^{3}$

(2) Can end volumes $=2 \pi(5.15 \mathrm{~cm})^{2} * 0.025 \mathrm{~cm} \approx 4 \mathrm{~cm}^{3}$

(3) Assume crimp volumes equal to one can end to estimate equivalent weight.

(4) Total volume $=10+4+2=16 \mathrm{~cm}^{3}$

ii. Weight of structural metal in can $=16 \mathrm{~cm}^{3} * 8 \mathrm{~g} / \mathrm{cm}^{3} \approx 130 \mathrm{~g}$

b. System heat capacity

System heat capacity $=(1000 \mathrm{~g} / 1130 \mathrm{~g}) * 3.6 \times 10^{-2} \mathrm{cal} / \mathrm{g} \mathrm{K}+(130 \mathrm{~g} / 1130 \mathrm{~g}) *$ $0.12 \mathrm{cal} / \mathrm{g} \mathrm{K}) \approx 0.05 \mathrm{cal} / \mathrm{g} \mathrm{K}$

c. Temperature Rise

Temperature rise $=1560 \mathrm{cal} /(0.05 \mathrm{cal} / \mathrm{g} \mathrm{K} * 1130 \mathrm{~g}) \approx 30 \mathrm{~K}$

\section{D.3. Conduction and Radiation Sample Calculations}

In response to potential concerns that uneven heat distribution across the metal could allow ignition to occur in an isolated area, the following calculation was performed to support experimental observations that bulk temperature must approach the ignition point before a significant metal fire can be sustained.

Conduction losses are estimated assuming the heat of reaction has been concentrated in one cubic centimeter at the corner of the plutonium piece sufficiently to allow the temperature in that corner to reach $500^{\circ} \mathrm{C}$ (i.e. just below the ignition temperature). The opposite sides of the plutonium piece are assumed to be at ambient temperature $\left(35^{\circ} \mathrm{C}\right)$. The only conduction initially considered is 
through three one square centimeter rectangles aligned with the three sides of the heated cube facing the metal. The heat transfer rate through any one of these rectangles can be determined from the equation

where

$$
\mathrm{Q} / \mathrm{A}=\mathrm{k} *\left(\mathrm{~T}_{1}-\mathrm{T}_{2}\right) / \mathrm{B}
$$

$$
\begin{aligned}
& Q=\text { heat flow (calories } / \mathrm{sec}), \\
& A=\text { Surface area of transfer }\left(\mathrm{cm}^{2}\right), \\
& k=\text { thermal conductivity }\left(\mathrm{cal} / \mathrm{cm}^{\circ} \text { sec }{ }^{\circ} \mathrm{C}\right), \\
& \mathrm{T}_{1}=\text { warm face temperature }\left({ }^{\circ} \mathrm{C}\right), \\
& \mathrm{T}_{2}=\text { cold face temperature }\left({ }^{\circ} \mathrm{C}\right), \text { and } \\
& \mathrm{B}=\text { thickness }(\mathrm{cm}) .
\end{aligned}
$$

A typical value for plutonium thermal conductivity between the assumed temperature values would be $0.03 \mathrm{cal} / \mathrm{cm} \mathrm{sec}{ }^{\circ} \mathrm{C}$. The thickness of the rectangles on any side of the heated cube is $2.7 \mathrm{~cm}$, resulting in a heat flux of $5.2 \mathrm{cal} / \mathrm{cm}^{2} \mathrm{sec}$. For the three one square centimeter faces of the cube, the total heat flux is $\approx 940 \mathrm{cal} / \mathrm{min}$.

Radiation heat losses from the heated cube can be estimated from the equation

$$
\mathrm{Q} / \mathrm{A}=\mathrm{s}^{*} \mathrm{E} *\left(\mathrm{~T}_{1}{ }^{4}-\mathrm{T}_{2}{ }^{4}\right)
$$

where

$$
\begin{aligned}
& Q=\text { heat flow (calories } / \mathrm{sec}), \\
& A=\text { Surface area of transfer }\left(\mathrm{cm}^{2}\right), \\
& S=1.355 \times 10^{-12} \mathrm{cal} / \mathrm{sec} \mathrm{cm}^{2} \mathrm{~K}^{4}, \\
& \mathrm{E}=\text { emissivity (dimensionless), } \\
& \mathrm{T}_{1}=\text { radiating temperature }(\mathrm{K}), \text { and } \\
& \mathrm{T}_{2}=\text { ambient temperature }(\mathrm{K}),
\end{aligned}
$$

The metal surface must be considered to be heavily oxidized to support the reaction being postulated, so an average emissivity value of 0.8 for oxidized metal surfaces is assumed. For the 3 square centimeters of radiating surface, the radiant heat loss is $68 \mathrm{cal} / \mathrm{min}$. Without considering conductive heat losses to the majority of the plutonium, radiative heat losses from the majority of the plutonium, or convective heat losses at all, it is easy to postulate a total heat loss of at least $1000 \mathrm{cal} / \mathrm{min}$ for a small, high temperature portion of a plutonium mass.

\section{D.3.a. Results}

Additional calculations were performed for a 1 kilogram mass of plutonium. Estimates for heat liberation were performed for oxygen limited reactions for hydride and for plutonium metal converting to oxide in instantaneous reactions that are not physically credible. Additional estimates were performed for instantaneous reaction of an estimated bounding corrosion composition of 2.3 grams plutonium hydride, 0.2 grams plutonium metal fines, and 42.5 grams of sub-stoichiometric oxide. For the oxygen limited hydride case, the maximum temperature rise of the plutonium was $30-43^{\circ} \mathrm{C}$, depending on whether the heat liberated was presumed to be transmitted to the can and the plutonium or the plutonium only. The heat liberated was 1,580 calories. For the metal oxidation case, the temperature rise and heat liberated were $43-61^{\circ} \mathrm{C}$ and 2,200 calories respectively. The values for the bounding corrosion estimate were $68-97^{\circ} \mathrm{C}$ and 3,500 calories. 


\section{D.4. Mechanical Energy Equivalent in Pressurized Storage Containers.}

The venting energy itself would present no threat as can be demonstrated by a simple TNTequivalent estimation using the equation for isentropic expansion of an ideal gas:

$$
\mathrm{E}=\left[\left(\mathrm{P}_{1} * \mathrm{~V}_{1}\right) /(\mathrm{y}-1)\right] *\left[1-\left(\mathrm{P}_{2} / \mathrm{P}_{1}\right)(\mathrm{y}-1) / \mathrm{y}\right]
$$

where

$$
\begin{aligned}
& E=\text { energy released (liter-atm), } \\
& P_{1}=\text { maximum pressure in can at time of venting (atm), } \\
& V_{1}=\text { volume of container }(1), \\
& y=\text { heat capacity ratio of gas }=1.4 \text { for air, and } \\
& P_{2}=\text { ambient pressure vented to }(\mathrm{atm}) .
\end{aligned}
$$

As shown in Appendix C, A typical maximum pressure within a can of certified oxide might be as high as $150 \mathrm{psi}(10.2 \mathrm{~atm})$. The typical primary container has a volume on the order of 1 liter, and the ambient pressure is $1 \mathrm{~atm}$. With 1 liter-atm being equivalent to 24.1 calories, and 1,120 calories being equivalent to one gram of TNT, the maximum TNT equivalent of this venting would $b e \approx 0.25$ grams of TNT, a value well below the average firecracker. However, storage of uncharacterized oxide could potentially yield far greater pressures. For example, the maximum pressure that might occur in the storage can with $3000 \mathrm{~g}$ of oxide is derived from Figure 1 . The oxide is assumed to be "wet" and to have a specific surface area of $50 \mathrm{~m}^{2} / \mathrm{g}$ (a value commonly seen for process oxide). Since the amount of water remaining after evacuation at room temperature is $28 \mathrm{mg} / \mathrm{g}$ for a specific surface area of $17 \mathrm{~m}^{2} / \mathrm{g}$, the loading on a $50 \mathrm{~m}^{2} / \mathrm{g}$ oxide is nearly $82 \mathrm{mg} \mathrm{H}_{2} \mathrm{O} / \mathrm{g} \mathrm{PuO}_{2}$. For $3 \mathrm{~kg}$ of oxide, the total amount of water in the container is, thus, $246 \mathrm{~g}$ (13.7 moles). If this quantity of water is radiolyzed to $\mathrm{H}_{2}$ and $\mathrm{O}_{2}$, the internal pressure in a 11 container is approximately $7500 \mathrm{psi}$ at $25^{\circ} \mathrm{C}$. However, since radiolysis is a slow process and containment will likely be lost at lower pressure as a result of structural failure, explosive release of gas at this pressure is highly unlikely. Simple thermal desorption of this quantity of water could result in a rapid rise in steam pressure to nearly $5000 \mathrm{psi}$. This event could result in considerable plutonium dispersal, equivalent to $14.8 \mathrm{~g}$ of TNT.

Last, recall that the radiolytic generation of hydrogen and oxygen could result in the formation of explosive gas mixtures. The energy equivalent in such mixtures would be considerable. It is difficult to quantify this process. A worst-case estimate yields nearly $150 \mathrm{~g}$ TNT-equivalent if all of the water present on oxide is radiolytically converted to hydrogen and oxygen in a typical storage container. Further work is necessary to determine the probability of this occurrence. Some evidence suggests that the plutonium dioxide surface may act as a catalyst for hydrogen/oxygen recombination. 